\title{
Population genetic structure and evolutionary history of Psammochloa villosa (Trin.) Bor (Poaceae) revealed by AFLP marker
}

\author{
$\mathrm{Xu} \mathrm{Su}{ }^{1}$ and Ting $\mathrm{Lv}^{2}$ \\ ${ }^{1}$ Qinghai Normal University \\ ${ }^{2}$ Affiliation not available
}

February 18, 2021

\begin{abstract}
We sought to generate a preliminary demographic framework for Psammochloa villosa to support of future studies of this ecologically important desert grass species, its conservation, and sustainable utilization. Psammochloa villosa occurs in the Inner Mongolian Plateau where it is frequently the dominant species and is involved in sand stabilization and wind breaking. Here, we characterized the genetic diversity and structure of 210 individuals from 43 natural populations of P. villosa using amplified fragment length polymorphism (AFLP) markers. We obtained 1728 well-defined amplified bands from eight pairs of primers, of which 1654 bands (95.72\%) were polymorphic. All these values indicate that there is abundant genetic diversity, but limited gene flow in P. villosa. However, an analysis of molecular variance (AMOVA) showed that genetic variation mainly exists within 43 populations of the species $(64.16 \%)$, and we found that the most genetically similar populations were often not geographically adjacent. Thus, this suggests that the mechanisms of gene flow are surprisingly complex in the species and may occur over long distances. In addition, we predicted the distribution dynamics of P. villosa based on the spatial distribution modeling and found that its range has contracted continuously since the last inter-glacial period. We speculate that dry, cold climates have been critical in determining the geographic distribution of P. villosa during the Quaternary period. Our study provides new insights into the population genetics and evolutionary history of P. villosa in the Inner Mongolian Plateau, which can be used to design in-situ conservation actions and to prioritize sustainable utilization of germplasm resources.
\end{abstract}

Population genetic structure and evolutionary history of Psammochloa villosa(Trin.) Bor (Poaceae) revealed by AFLP marker

Running Head: Population genetic structure of $P$. villosa

Ting Lv ${ }^{1,2}$, AJ Harris ${ }^{3}$, Tao Liu ${ }^{1,2}$, Ruifang Liang ${ }^{4,5}$, Zilan Ma ${ }^{4,5}$, Yuping $\mathrm{Liu}^{* 4,5}, \mathrm{Xu} \mathrm{Su}^{* 1,2,4,5}$

1 School of Geosciences, Qinghai Normal University, Xining 810008, P. R. China

2 Key Laboratory of Education Ministry of Earth Surface Processes and Ecological Conservation of the Qinghai-Tibet Plateau, Qinghai Normal University, Xining 810008, P. R. China

3 Key Laboratory of Plant Resources Conservation and Sustainable Utilization, South China Botanical Garden, Chinese Academy of Sciences, Guangzhou 510650, P. R. China

4 Key Laboratory of Medicinal Plant and Animal Resources of the Qinghai-Tibet Plateau in Qinghai Province, School of Life Science, Qinghai Normal University, Xining 810008, P. R. China

5 Academy of Plateau Science and Sustainability, Xining 810016, P. R. China

${ }^{*}$ Correspondence to: 
Xu Su - Phone: +86 971 6134763; fax: +86 971 6134763; E-mail address: xusu8527972@126.com

OR

Yuping Liu - Phone: +86 971 6134763; fax: 86971 6134763; E-mail address: lyp8527970@126. com

AJ Harris contributed equally to this work.

\section{Abstract}

We sought to generate a preliminary demographic framework for Psammochloa villosa to support of future studies of this ecologically important desert grass species, its conservation, and sustainable utilization. Psammochloa villosa occurs in the Inner Mongolian Plateau where it is frequently the dominant species and is involved in sand stabilization and wind breaking. Here, we characterized the genetic diversity and structure of 210 individuals from 43 natural populations of $P$. villosa using amplified fragment length polymorphism (AFLP) markers. We obtained 1728 well-defined amplified bands from eight pairs of primers, of which 1654 bands $(95.72 \%)$ were polymorphic. Results obtained from the AFLPs estimated a number of effective alleles among populations of 1.3229, a Nei's standard genetic distance value of 0.2056 , a Shannon index of 0.3316, a coefficient of gene differentiation $\left(G_{\mathrm{ST}}\right)$ of 0.4689 , and a gene flow parameter $(N \mathrm{~m})$ of 0.5761 . All these values indicate that there is abundant genetic diversity, but limited gene flow in $P$. villosa . However, an analysis of molecular variance (AMOVA) showed that genetic variation mainly exists within 43 populations of the species $(64.16 \%)$, and we found that the most genetically similar populations were often not geographically adjacent. Thus, this suggests that the mechanisms of gene flow are surprisingly complex in the species and may occur over long distances. In addition, we predicted the distribution dynamics of $P$. villosabased on the spatial distribution modeling and found that its range has contracted continuously since the last inter-glacial period. We speculate that dry, cold climates have been critical in determining the geographic distribution of $P$. villosa during the Quaternary period. Our study provides new insights into the population genetics and evolutionary history of $P$. villosa in the Inner Mongolian Plateau, which can be used to design in-situ conservation actions and to prioritize sustainable utilization of germplasm resources.

Keywords: desert grasslands; population genetics; SAMOVA; ecological niche modelling; Inner Mongolian Plateau;

Psammochloa villosa

\section{Introduction}

The Quaternary period, comprising the Holocene and Pleistocene Epochs, spanned the last $\sim 2.6$ million years (Myr) and has been characterized by distinct climatic oscillations, especially alternating glacial and interglacial cycles in the Northern Hemisphere (Shackleton \& Opdyke, 1973; Pillans \& Gibbard, 2012; Elias, 2013). The glacial cycles co-varied with, and probably profoundly affected, other aspects of the climate, including the intensity of the Asian monsoon, even in unglaciated regions (An, Kutzbach, Prell, \& Porter, 2001; Jiang, Lang, Tian, \& Guo, 2011; Liu et al., 2018). Climate fluctuations during the Quaternary glaciations led to dramatic changes in the geographical distribution, genetic structure, and population demography of plant species (Hewitt, 2000; Wang et al., 2009; Jia et al., 2012; Liu et al., 2018).

Quaternary climate change is known to have strongly affected the distributions of plants in Northern China (Tian et al., 2009; Qiu, Fu, \& Comes, 2011; Liu, Sun, Ge, Gao, \& Qiu, 2012). Northern China is dominated by deserts, which developed in the Quaternary to due to sustained orogenesis of the Qinghai-Tibetan Plateau and surrounding areas that ultimately enhanced aridity within the region $(\mathrm{Wu}, 1992,2002$; Meng \& Zhang, 2011). The climatic processes that gave rise to the deserts also shaped regional plant diversity and yielded highly complex demographic histories of native species (Ge, Yu, Yuan, Huang, \& Yan, 2005; Ge et al., 2011; Yang, Fang, Dong, Peng, \& Li, 2006). In particular, many plants within the deserts of Northern China underwent adaptive and demographic change in response to cold, arid conditions, which occurred during the intermittent glacial periods and which may be primary mechanisms explaining modern distributions (e.g., Comes \& Kadereit, 1998; Hewitt, 2000; Ge et al., 2011; Zhang \& Zhang, 2012; Su \& Zhang, 2013; Zhang, 
Zhang, \& Williams, 2014; Xu \& Zhang, 2015; Shuyskaya, Toderich, Gismatullina, Rajabov, \& Khohlov, 2017; Merklinger et al., 2019; El-Tayeh, Galal, Soliman, \& Zaki, 2020). For example, Su \& Zhang (2013) proposed that the onset of aridity during Quaternary glacial periods was a primary driver of population processes and structures in Nitraria sphaerocarpa Maxim. (Nitrariaceae, Sapindales), and Xu \& Zhang (2015) revealed that periods of cold, arid conditions during the Pleistocene glaciations resulted in the genetic differentiation and demographic structuring in Atraphaxis frutescens (L.) K.Koch (Polygonaceae).

Nevertheless, these prior studies on population histories of desert plants of Northern China have focused primarily on woody species. Studies on herbs of the region are largely lacking, and to our knowledge, the only such study is on Delphinium naviculare W. T. Wang (Ranunculaceae) (Zhang \& Zhang, 2012), which is endemic at mid-elevations within the Tianshan Mountains of Xinjiang Province of China (Wang \& Warnock, 2001). Herbaceous plants of the deserts of Northern China merit further study because they comprise a vital component of desert plant communities, and studies focusing on dominant grass species are especially warranted (Meng \& Zhang, 2011). Herbaceous plants may have been more sensitive to Quaternary climatic oscillations because they differ markedly from woody species in their response to cold, often via death of aboveground biomass as either part of an annulment or perennial life cycle. Moreover, dominant species likely achieved their abundance due to their responses to the glacial cycles.

In modern times, deserts and semi-deserts, such as in Northern China, are extremely fragile ecosystems, the stability of which impacts global environmental conditions and influences climate change ( $\mathrm{Su}, 2013)$. Although deserts typically have sparse vegetation, plants are critical for maintaining their integrity. In Northern China, the desert grassland ecosystems in particular are becoming rapidly degraded due to longterm overgrazing and desertification and, simultaneously, desert is encroaching on arable land within the region (Li, Liu, \& Wang, 2004; Hanafi \& Jauffret, 2008; Wang, 2009; Peters, Yao, Sala, \& Anderson, 2012; Deng, Zhang, \& Shangguan, 2014; State Forestry Administration, 2015; Wang \& Zhou, 2015; Wei, Wang, \& $\mathrm{Niu}, 2020$ ). These desert grasslands represent a large area within China and adjacent countries and occur at both low and high elevations. Dominant plant species within the grasslands are often psammophytes, which have special adaptations to resist being buried by sand and to tolerate having periodically exposed roots. Simultaneously, these plants help to anchor sands in place and prevented wind erosion, and are thus critical for promoting environmental stability within their ecosystems (Ma, 1991; Pan, 2006; Zhou, Yuan, \& Jing, 2011).

In this study, we focus on one psammophyte, Psammochloa villosa(Trin.) Bor, which comprises a monotypic genus in tribe Stipeae of Poaceae. This species, commonly called sand whip, is a perennial rhizomatous herb that is primarily distributed in the desert grasslands of northwestern China, especially the Inner Mongolian Plateau, the Hexi Corridor of Gansu, central and Northern Ningxia, and Northern Shanxi (Liu, 1985; Ma, 1994; Huang, 2003). It also occurs in Mongolia. The flowering and fruiting period of $P$. villosa is from September to November, and the seeds are $5-7 \mathrm{~mm}$ long with an average weight of $5.507 \pm 0.053 \mathrm{mg}$ (Huang, 2003). Such light seeds are likely dispersed by high winds that occur throughout much of its natural desert habitat. Nevertheless, seedlings are rarely observed (Zhu, 2005).Psammochloa villosa is known to have high resistance to drought, cold, alkaline soils, disease, wind, and burial by sand, all of which likely represent evolutionary adaptations and facilitate its survival in grassland and dune areas (Lu, 1987; Huang, 1995, 1997; Wu \& Phillips, 2006). Previous research on P. villosa has been mainly focused on studying its anatomy, embryology and microbiology (e.g., Dong \& Alaten, 1999; Huang, Dong, \& Gutterman, 2004; Wang et al., 2011; Zhang et al., 2017; Lv et al., 2018), with few studies so far focused on molecular markers (e.g., Li \& Ge, 2001). The species is ecologically widespread at low and high elevations (900-2900 m) (Kuo, 1987; Wu \& Phillips, 2006).

In our present study, we investigated the influence of climate aridification and oscillations on the genetic structure and evolutionary processes of $P$. villosaduring the Quaternary in north-western China using amplified fragment length polymorphism (AFLP) markers and ENM. We used AFLPs because they remain extremely efficient for investigating genetic diversity, genetic structure, and population demography due to their high levels of polymorphism (Wang, Wang, Liu, Yang, \& Chen, 2008), their reproducible, reliable re- 
sults that are unaffected by the developmental stage of plant materials, and their universality among plant species. In addition, they have been used to resolve genetic structures and population demography in many diverse grass species such as Oryza sativa, Leymus racemosus, Orinus thoroldii and O. kokonoricus (Zhang \& Jia, 2002; Sim, 2005; Li, 2015; Cai, 2017; Liu, Harris, Gao, Su, \& Ren, 2019). Our main objectives were to (1) analyze the genetic structure from 43 populations of $P$. villosa from Inner Mongolian Plateau using an AFLP dataset, (2) test whether historical genetic divergence occurred among populations in response to Quaternary climate oscillations, and (3) evaluate the abiotic factors that are most influential in driving the distributions of $P$. villosa . Moreover, because no assessment of the conservation needs of $P$. villosa had previously been accomplished, we also performed a preliminary assessment based on Extent of Occurrence (EOO) with interpretation according to guidelines of the International Union for the Conservation of Nature (IUCN). We believe that, taken together, our results can provide a scientific basis for improved protection and sustainable utilization (e.g., as forage) of $P$. villosa within the fragile desert grassland ecosystems of Northern China.

\section{Materials and Methods}

\subsection{Population sampling}

We collected a total of 210 individuals from 43 populations of $P$. villosa in the field throughout its natural range in China (Table S1 \& (Figure S1) and randomly sampled five to ten individuals from each population. We sampled individuals $20 \mathrm{~m}$ apart to avoid sampling a single clone more than once. In the field, we immediately put the fresh leaves into sealed bags filled with silica gel and then stored them in the laboratory in a -20 freezer until processing. We deposited one voucher specimen representing each population in the Herbarium of Qinghai-Tibet Plateau Museum of Biology (QTPMB), Northwest Institute of Plateau Biology, Chinese Academy of Sciences, China.

\subsection{DNA extraction and AFLP genotyping}

We extracted total DNA from each sample according to a modification of the CTAB procedure (Doyle \& Doyle, 1987) and accessed DNA quality using 1.0\% agarose gel electrophoresis and A260/A280 ratio determined on a Nanodrop 2000c. Our procedure to obtain AFLPs was based on a modification of the method in Vos et al. (1995). First, we digested the genomic DNA with the restriction enzymes EcoR I and $M s e I$ for $5 \mathrm{~h}$ at $37 \mathrm{degC}$, and ligated the adaptors of EcoR I andMse I to the digestion products over night at $4 \operatorname{deg} \mathrm{C}$ (Beijing Dingguo Biotechnology Co., Ltd). Using the digested products, we performed a two-stage PCR amplification comprising pre-amplification and selective amplification. The selective amplification was conducted in $25 \mu \mathrm{l}$ volume of reaction mixture containing of $1.0 \mu \mathrm{l} E c o R \mathrm{I} / \mathrm{Mse}$ I primer combinations (AAC/CAA, AAG/CAC, ACA/CAG, ACT/CAT, ACC/CTA, ACG/CTC, AGC/CTG, AGG/CTT; Table 1). Subsequently, we separated the fluorescently-labeled fragments on an ABI PRISM 377 DNA Calibrator (Applied Biosystems) using GeneScan ROX-500 with an internal size standard, allowing visual inspection of all individual sites (Liu, Harris, Gao, Su, \& Ren, 2019). We recorded the presence or absence of AFLP amplification bands (Figure S2) in a binary matrix as 1 or 0 , respectively, based on interpretations from GeneScan 3.1 (Applied Biosystems). In total, we assessed 1728 AFLP markers for the 210 individuals, and all interpretations were performed randomly.

\subsection{Genetic diversity and population genetic structure}

For each population, we evaluated genetic diversity and population genetic structure according to standard metrics in POPGENE 1.32 (Wang, 1996; Yeh, Yang \& Boyle, 1999). These metrics included the number of individuals $(\mathrm{N})$, percentage of polymorphic loci (PPL), observed number of alleles $(N$ a), effective number of alleles $(\mathrm{Ne})$, Shannon's information index ( $I$; Lewontin, 1972), expected heterozygosity ( $H$ e; Kimura \& Crow, 1964), Nei's genetic diversity $(h)$, total gene diversity $(H$ t), the average gene diversity within populations $(H \mathrm{~s})$, and Nei's standard genetic distance (GD). We also calculated the degree of genetic differentiation between populations $\left(G_{\mathrm{ST}}\right)$ as $(H \mathrm{t}-H \mathrm{~s}) / H \mathrm{t}$ (Nei, 1973) and the parameter of gene exchange as $N \mathrm{~m}=0.5\left(1-G_{\mathrm{ST}}\right) / G_{\mathrm{ST}}$ (McDermott \& McDonald, 1993). Similarly, we estimated parameters of genetic diversity, coefficients of gene differentiation and gene flow for eight pairs of AFLP primers. 
In order to search for partitions of sampling sites genetically homogenous but maximally differentiated from each other, we conducted a spatial analysis of molecular variance using SAMOVA 1.0 (Dupanloup, Schneider, \& Excoffier, 2002) based on AFLP datasets. Within SAMOVA, we used a $K$-means method to select the best clustering among groups of populations based on genetic variation coefficients $\left(F_{\mathrm{CT}}\right)$ (Li et al., 2020). For values of $K$ in the range two to ten, we set simulated annealing processes to 100 with 10,000 steps each. We selected the value of $K$ that $\operatorname{maximized} F$ CT values as the optimal grouping of populations. Using this optimal grouping, we evaluated the genetic variation between populations within groups and between groups in SAMOVA 1.0 via an analysis of molecular variance (AMOVA, Excoffier, Smouse, \& Quattro, 1992) in ARLEQUIN v3.01 (Excoffier, Laval, \& Schneider, 2005). Neutrality tests, such as Tajima's $D$ and Fu's Fs , were also calculated with this program. Subsequently, we determined the correlation between $F$ ST inferred from the binary matrix of scored AFLPs and geographic distance of the populations via a Mantel test (Mantel, 1967) in GenAlEx 6.5 (Peakall \& Smouse, 2012) with 9999 permutations to evaluate significance.

To further investigate the genetic associations among 43 populations of $P$. villosa, we used the SAHN module in NTSYS-pc 2.10e (Rohlf, 1997) to generate a UPGMA tree from the genetic distance matrix derived from the binary AFLP dataset, and also carried out a principal coordinate analysis (PCoA) based on the distance matrix. Moreover, we constructed a similarity-based network in SplitsTree 4.13 (Huson \& Bryant, 2006) to infer the relationships between individuals and populations by applying the Neighbor-Net algorithm with the Jaccard's measure of distance.

In addition, we inferred groupings and genetic structures of populations of $P$. villosa using STRUCTURE V2.2 (Pritchard, Stephens, \& Donnelly, 2000; Falush, Stephens, \& Pritchard, 2007; Hubisz, Falush, Stephens, \& Pritchard, 2009), which differs from SAMOVA by not requiring that groupings be geographically adjacent. In STRUCTURE, we performed the analyses using an admixture model with independent allele frequencies for 90 independent runs for the number of clusters $(K)$ ranging from one to ten. We applied $2 \times 10^{5}$ repetitions of the Markov chain Monte Carlo with a burn-in of $25 \%$. To determine the best value of $K$ for the STRUCTURE analyses, we used the $\Delta K$ statistical method (Evanno, Regnaut, \& Goudet, 2005).

\subsection{Distribution modeling of $\boldsymbol{P}$. villosa}

In order to predict the impact that Quaternary climatic oscillation might have on the geographic distribution change of $P$. villosa, we employed an ecological niche modelling (ENM) approach to evaluate the potential distribution of $P$. villosa at the Last Inter-Glacial (LIG, $\sim$ 120,000 - 140,000 years before present), the Last Glacial Maximum (LGM, 21,000 years before present), the present and future times (2050s and 2070s), respectively. In addition to the distribution records of our field surveys, we also collected GPS data from the Chinese Virtual Herbarium (CVH, http: //www.cvh.ac.cn), Global Biodiversity Information Facility (http: //www. gbif.org), China National Specimen Information Infrastructure (http://www.nsii.org.cn) and Specimen Resources Sharing Platform for Education (http://mnh.scu.edu.cn/main.aspx) for P. villosa. In total, after removing duplicate and ambiguous records, we used 155 localities to generate spatial distribution models for P. villosa(Table S2). To improve abilities in establishing high-resolution predictions and identifying the critical factors influencing the species' distribution, we obtained 19 bioclimatic variables and three geographic factors, such as altitude, slope and aspect, at 2.5 arc-min resolution from WorldClim database (Hijmans, Cameron, Parra, Jones, \& Jarvis, 2005, www.worldclim.org). The future climate data involved in two emission scenarios of representative concentration pathways (RCP8.5 and RCP2.6) with the CCSM4 model (Van et al., 2011). We excluded highly correlated variables according to Spearman's correlation test (Peterson \& Nakazawa, 2008). Specifically, we selected the variables with a relative contribution score [?] 0.8 or a correlation of $<0.75$ compared to other variables. Based on the outcome of Spearman's, we retained the eleven variables with the lowest correlations to build a maximum entropy model for the habitat of $P$. villosa using. Subsequently, we generated this model representing the potential distribution of $P$. villosa in environmental space in MaxEnt 3.3.3k (Phillips, Anderson, \& Schapire, 2006; Phillips \& Dudik, 2008). Within MaxEnt, we performed modeling with $75 \%$ of localities randomly selected for training and $25 \%$ selected for testing 500 times independently to ensure reliable results, and we evaluated model performance using the area under the curve (AUC) of receiver operating characteristic (ROC). The value of AUC ranges 
between 0 (randomness) and 1 (exact match), and the value above 0.9 indicated good performance of the model (Swets, 1988). Additionally, we projected the predicted geographic ranges of species based on the ENMs using ArcGIS 10.2. In particular, we divided suitable habitat into four classes: highly suitable habitat (0.5 [?] $P$ [?] 1.0), moderately suitable habitat $(0.3$ [?] $P<0.5)$, poorly suitable habitat $(0.1[?] P<0.3)$ and unsuitable habitat $(0.0$ [?] $P<0.1)$.

In order to measure the niche similarity between populations occurring in groups, we calculated Schoener's $D$ (Schoener, 1968) and standardized Hellinger distance (calculated as $I$ ) in ENMTools 1.3 (Warren, Glor, \& Turelli, 2008, 2010). We obtained the null distribution of niche models in the identity test based on 1000 pseudo replicates generated by random sampling from the data points pooled for each pair of cluster. We determined measures of niche similarity $(D$ and $I$ ) by comparing with null distributions drawn from pooled occurrences retaining original cluster size, and we drew histograms of frequency distributions using $\mathrm{R} 2.13$ (http://www.r-project.org/).

\subsection{Conservation assessment of $P$. villosa}

We performed a conservation assessment using the Extent of Occurrence (EOO) (Moat, 2007; Velzen \& Wieringa, 2014) and following guidelines for their interpretation from IUCN (2001). EOO comprises the minimum convex polygon covering all known or predicted sites for the species. It is frequently used as a preliminary assessment tool, such as when a new species is described or when populations of a species are found in new places or were locally extirpated (e.g., Velzen \& Wieringa, 2014; Lachenaud et al., 2013). In the case of $P$. villosa, there had been no prior conservation assessment for the species, and it status is not presently included in the IUCN Red List of Threatened Species (IUCN, 2020). Therefore, we analyzed the EOO using the location data of 155 populations from ecological niche model (Table S2).

\section{Results}

\subsection{Polymorphism of AFLP markers}

The eight primer pairs yielded 1728 clearly identifiable amplified bands, of which 1654 (95.72\%) were polymorphic (Table 2). Different primers yielded different numbers of bands ranging from 214 ( $E$-ACG/M -CTC) to 199 ( $E$-AGC/ $M$-CTG and $E-\mathrm{AAG} / M$-CAC) with an average of 207. The highest rate of polymorphism for an individual primer was $99.07 \%$, and the lowest was $92.13 \%$. Overall, these eight primers showed high levels of polymorphism among individuals of $P$. villosa .

The indices, $N$ a, $N$ e, $h$, and $I$ were important indicators of genetic diversity of populations. According to the genetic diversity index of eight primer pairs, the indices of $N$ a, $N$ e, $h$ and $I$ ranged from 1.9950 to 2.0000 with an average of $1.9994,1.2898$ to 1.3445 with an average of $1.3229,0.1926$ to 0.2131 with an average of 0.2056 , and 0.3183 to 0.3379 with an average of 0.3316 , respectively. Overall, these indices showed the highest genetic diversity for the primer pair of $E-\mathrm{AGG} / M-\mathrm{CAC}$, while the lowest was for $E-\mathrm{ACT} / M$ -CTT. In general, each of eight primer pairs appeared to facilitate a robust assessment of genetic diversity in P. villosa .

\subsection{Population Grouping}

Based on SAMOVA, we found that the $F_{\mathrm{CT}}$ value was the highest when $K=3$, which resulted in separation of populations into three groups. Among them, both the first group (P1-6) and the second group (P7-12) contained six populations, and the third group consisted of all other populations. However, three populations (P6-8) were highly similar in their geographic distributions and their habitats according to our field surveys, and this was why we did not adopt $K=4$. When $K$ was $>4$, at least one group consisted of a single population (Table S3), indicating over-splitting and loss of geographic structural data. Thus, we thought it was the most reasonable to divide 43 populations of $P$. villosainto two major groups.

The first group, Group 1, identified using SAMOVA, consisted of 12 populations (P1-12), which mainly occurred in the central and eastern regions of the Inner Mongolian Plateau, while the second one, Group 2, was composed all other populations, which distributed throughout the range of the species in China. Notably, 
the populations of Group 1 tend to be found at lower elevations compared to those from Group 2 (Table S1 \& Figure S1). Groupings of populations can facilitate detection of finer scale geographic structures (i.e., within groups) juxtaposed with broader, regional patterns (i.e., between groups) (Li et al., 2020). Therefore, we used the recovered grouping scheme for downstream data analysis in our present study.

\subsection{Genetic diversity of populations}

The percentage of polymorphic loci (PPL), observed number of alleles $(N$ a), effective number of alleles $(N$ e), expected heterozygosity $(H$ e) and Shannon information index $(I)$ of 43 populations were from 19.23 to $54.29,0.5012$ to $1.1155,1.1315$ to $1.2908,0.0791$ to 0.1771 and 0.1163 to 0.2709 , respectively. The PPL, $N$ a, $N$ e, $H$ e, $I$ of populations from Group 1 were $32.63,0.7193,1.1848,0.1100$ and 0.1667 , respectively, while those of Group 2 were 32.02, 0.7322, 1.1817, 0.1082 and 0.1640 (Table S1). The genetic diversity indices showed the populations of Group 2 exhibited greater variability than those of Group 1. However, the difference of genetic diversity between two groups was minimal. Overall, the results of genetic diversity analyses from 43 populations of $P$. villosasuggested that there was abundant genetic diversity of this species within the Inner Mongolian Plateau.

\subsection{Genetic differentiation and distance of populations}

The genetic differentiation analyses based on 43 populations of $P$. villosa revealed that the total gene diversity $(H \mathrm{t})$ was 0.2052 , the average gene diversity within populations $(H \mathrm{~s})$ was 0.1088 , the genetic differentiation between populations $\left(G_{\mathrm{ST}}\right)$ was 0.4689 , and the gene flow $(N \mathrm{~m})$ was 0.5761 . The value of $N \mathrm{~m}$ indicated that a limited level of gene exchange existed within the species (Table 3). With respect to populations of Group 1, the values of $H \mathrm{t}, H \mathrm{~s}$ and $G$ ST were $0.1668,0.1102$, and 0.3402 , respectively, while these were $0.1918,0.1083$, and 0.4349 for Group 2. Thus, the genetic diversity of Group 1 was lower than that of Group 2 , and the genetic differentiation was smaller. The gene flow among populations within Group 1 and Group 2 was 0.9996 and 0.6605 , respectively, which revealed that the gene exchange among populations within Group 1 was more frequent.

\subsection{Population genetic structure}

Analysis of molecular variance (AMOVA) based on the AFLP dataset from 43 populations of P. villosa showed that the proportion of genetic variation among populations was $35.84 \%$, while that within populations was $64.16 \%$, and the value of average pairwise $F$ st was $0.35841(P<0.001)$ (Table 4$)$, which showed that the genetic variation of $P$. villosamainly occurred within populations. More interestingly, when aggregating populations into Groups 1 and 2, we found that $22.38 \%$ of the genetic variation occurred among populations within groups $\left(F_{\mathrm{CT}}=0.28501, P<0.001\right)$, while most of genetic variation $(56.14 \%)$ existed within populations $\left(F_{\text {ST }}=0.43865, P<0.001\right)$ (Table 4$)$. Overall, the genetic variation at the populationand local geographic-scale was much higher than regionally in $P$. villosa. Additionally, the result of neutrality test suggested the value of Tajima's $D$ and Fu's Fs was positive, but non-significant for all populations of $P$. villosa (Table 3 ).

The Mantel test revealed that there was a significant positive correlation between geographic distance and $F$ ST for 43 populations $(r=0.282, P<0.05)$ (Figure 1). Similarly, we detected a strong, significant, positive correlation between geographic distance and $F$ sT for Group $1(r=0.622, P<0.05)$ and a weak but significant positive correlation for Group $2(r=0.372, P<0.05)$. Simultaneously, results from UPGMA tree, SplitsTree network, PCoA, and STRUCTURE suggested that 43 populations of $P$. villosawere divided into two groups, which were largely consistent with our assessment using SAMOVA (Figure 2 - 5).

\subsection{Distributional change of $P$. villosa}

ENMs for P. villosa yielded relatively high AUC, demonstrating reliable model performance (AUC $=0.969$, Figure S3). For the eleven non-biological variables used for modeling, the most significant factor for the spatial distribution pattern of $P$. villosa was altitude (Alt), followed by temperature annual range (bio 7) and precipitation of warmest quarter (bio 18), whose contribution rates were $40.0 \%, 17.2 \%$ and $16.7 \%$, respectively (Table 5). In comparison with the LIG, we observed a contraction in highly suitable habitat 
during the LGM based on the MaxEnt models (Table 6 \& Figure 6). Similarly, the spatial distribution of the present was continuously shrinking compared to the potential range during the LGM (Figure 7). The simulated distribution based on present climate data was mostly congruent with the actual distribution range of $P$. villosa, which was mainly distributed in the Inner Mongolia Plateau with an area of approximately $111.2450 \times 10^{4} \mathrm{~km}^{2}$ (Table $6 \&$ Figure7). Simultaneously, we estimated the future changes in the potential spatial distribution under the RCP 2.6 and RCP 8.5 scenarios for the $2050 \mathrm{~s}$ and $2070 \mathrm{~s}$. According to the future model predictions, the areas of suitable habitat is likely to remain stable under the climatic scenario of RCP 2.6 for the 2050s and 2070s, whereas there was an increase of highly suitable areas based on RCP 8.5 (Table 7 \& Figure 8).

When we compared the niches of hypothesis of niche identity was rejected when the empirically observed value for $D$ and/or $I$ was significantly lower than the values expected from the pseudo-replicated data sets. Therefore, identity tests between two groups indicated that there was distinct niche differentiation $(P<$ 0.01) (Figure 9). The niche of two groups differs mainly in that it was characterized by high elevation and temperature.

\subsection{Conservation status of $P$. villosa}

IUCN is a global classification standard system for threatened species. Its main purpose is to provide a clear and objective framework for the classification of species according to their extinction risk. Psammochloa villosa qualifies as a species of least concern (LC) under the $\mathrm{EOO}$ criterion $\left(\mathrm{EOO}=2,064,370 \mathrm{~km}^{2}\right)$. However, after observing populations at 43 sampling locations during our field work, we noted that some populations of the species presently grew in severely degraded habitat. Thus, while this species was probably not currently threatened, decreases in its frequency within population and the abundance of populations could jeopardize its vital ecological role. Therefore, we advocate for continued ecological monitoring of this dominant, keystone desert grass species.

\section{Discussion}

\subsection{Genetic diversity of $P$. villosa}

Genetic diversity refers to intraspecific genetic variation and is closely linked to the evolutionary potential of a species to adapt to adverse environments (Ma \& Qian, 1994). The study of genetic diversity can facilitate understanding of spatial genetic patterns of a species, and elucidate its evolutionary processes and adaptive mechanisms (Hao, 2005). In the present study, we observed high genetic diversity at species-level in $P$. villosa $(P=95.72 \%, I=0.3316)$ and the population-level $(P=32.02 \%, I=0.1640)$ (Table $2 \&$ Table S1). Compared to genetic diversity in other species of Poaceae assessed using AFLPs, genetic diversity in $P$. villosa was slightly lower than that of Chascolytrum bulbosum $(P=98.2 \%, h=0.1500$; Silva, Essi, Welker, $\&$ de, Souza-Chies, 2016), and was higher than that of Leymus chinensis $(P=16.53 \%, I=0.0890)$, Leymus racemosus $(P=16.53 \%, I=0.0890)$, andDactylis glomerata $(P=61.70 \%, I=0.2664)$ (Gong et al., 2007; Cai, 2016; Zhang, He, Zhao, Zhang, \& Xu, 2017).

The underlying drivers of genetic diversity within species are generally a combination of biological properties, such as dispersal abilities and life history, and environmental factors, such as climate and anthropogenic activities (Loveless \& Hamrick, 1984; Hamrick \& Godt, 1996; Wang \& Hu, 1996; Wen, Han, \& Wu, 2010). The life history of $P$. villosa frequently involves clonal reproduction via its rhizomes under harsh environmental conditions, although the species reproduces sexually by seed following wind pollination (Wang, Ge, \& Dong, 1999; Li \& Ge, 2001). In comparison with L. chinensis, L. racemosus, and D. glomerata, the relatively high genetic diversity of $P$. villosa might be explained by one or more of several factors. Among these, our study design comprised more populations, which might lead to greater accuracy. However, biological explanations are more likely and include possible higher clonal fitness due to $P$. villosa having extremely robust, hardy rhizomes; high rates of seed production; and seedling regeneration, while rare within any one growing season, occurring often over the long lifetime of the species (Eriksson \& Bremer, 1993; Helena \& Mikko, 1996; Shimizu et al., 1998). 


\subsection{Genetic differentiation and genetic structure}

Genetic structure of a species is effectively the sum of genetic differentiation among and within populations (Hamrick \& Godt, 1989). Overall, genetic structure occurring among populations results from the evolutionary history of the species in question; natural selection; genomic factors (e.g., mutations, reorganization, and genetic drift); and biological characteristics, including gene flow, mating system, mode of reproduction, and seed dispersal mechanisms (Slatkin, 1987; Zhen, 2010). Genetic differentiation is primarily controlled by aspects of gene flow, such as its rate and directionality (Hamrick \& Godt, 1989). In plants, gene flow occurs primarily via the transmission of pollen and seeds during sexual reproduction. However, for clonal species, such as $P$. villosa, asexual propagules often have limited dispersal distance, and this restricts gene flow among populations (Xia, Li, \& Li, 2002).

For P. villosa, we inferred that more than $56 \%$ of the genetic variation existed within populations, with average pairwise $F$ ST of 0.35841 for all 43 population and gene flow $(N \mathrm{~m})$ of 0.5761 (Table 4$)$. According to Wright's (1978) theory, genetic differentiation among populations might be large when $F$ st $>0.25$, but this can be mitigated by gene flow of $N \mathrm{~m}>1$, which can reduce the effects of genetic drift and prevent genetic differentiation among populations. In $P$. villosa, we found high $F$ st but limited gene flow, which should yield high rates of between population differentiation. However, we found higher rates of within population differentiation for the species. This differs from findings in other studies of $P$. villosa that revealed greater genetic variation among populations, such as in Li \& Ge (2001), who studied genetic diversity in P. villosa using and seven populations, of which two were from Shihuimiao Ecological Station and five were from the Shilongmiao Ecological Station. Similarly, Wang et al. (1999) assessed the genetic diversity of four populations of $P$. villosa from mobile and fixed sand dunes in the Shihuimiao Ecological Station (two populations) and the Shilongmiao Ecological Station (two populations) and found greater genetic variation among populations. Nevertheless, population genetic structure was a comprehensive result of a variety of factors that were related to the evolutionary origins and modes of dispersal and sexual reproduction, which all might be unique to each population within a species (Wang, Ge, \& Dong, 1999). Accordingly, we inferred this inconsistency may be related to the numbers of populations and geographic location. Our sampling, which included a larger number of populations and a greater portion of the geographic range of $P$. villosa, might have yielded results that more robustly detect patterns among unique populations. In addition, the efficiency and accuracy of gene identification are also related to the number of polymorphic bands, and the results obtained by different experimental methods are different.

In this study, our SAMOVA analysis revealed two well-defined groups corresponding to Group1 and Group2 (Table S3). These groups are also consistent with our analyses using UPGMA, STRUCTURE, SplitsTree, and PCoA (Figure 2-5). Within populations of Groups 1 and 2, the average genetic variation was $64 \%$ with an average pairwise $F$ ST value of 0.43865 . The gene flow $(N \mathrm{~m})$ in Groups 1 and 2 was $0.9996,0.6605$, respectively (Table 4). In addition, the UPGMA tree revealed that populations with closer geographic distances did not always cluster together, and we observed a similar pattern in the results from STRUCTURE and SplitsTree. Similarly, the PCoA showed that individuals from the same population did not always group together, further indicating that, while gene flow may be limited in P. villosa, it occurs over long distances more often than between adjacent populations. This may suggest that some critical dispersal vector, such as birds, is yetunknown for the species. Overall, P. villosa has undergone considerable genetic divergence and has a high level of genetic structure based on the combined results from our population genetics analyses.

Based on a Mantel test, we found that there was significant correlation between genetic distance and geographic distance, indicating that geographic distance is an important factor affecting the genetic structure of P. villosa . Therefore, we inferred that genetic structure might have been resulted mainly from geographic isolation imposed by mountains (e.g., Yin Mountains; Helan Mountains) and large deserts in northwestern China (e.g. Tengger Desert; Mu Us Sandy Land) as well as range contraction and population fragmentation induced by climatic oscillations (e.g., Gymnocarpos przewalskii Maxim.;Helianthemum songaricum Schrenk) (Liu, 1995; Su, Zhang, \& Sanderson, 2011; Ma, Zhang, \& Sanderson, 2012; Meng, Gao, Huang, \& Zhang, 2014). In addition, founder effects and population bottlenecks might have also contributed to the genetic 
structures of the species (Birky, Fuerst, \& Maruyama, 1989; Liu et al., 2015).

\subsection{Demographic historyof $P$. villosa}

The genetic diversity within the Group 1, identified according to SAMOVA, was lower than that of the populations in Group 2 (Table 3). Based on this, extant populations of this species originated from the genetic stock of Group 2, as geographic areas with both high genetic diversity and frequency of dominant genes usually represent centers of origins for source populations (Vavilov, 1926). However, our study design and results cannot discern the exact center of origin for the species nor the main migrational patterns of $P$. villosa, and accomplishing this will require additional molecular data and informatics approaches.

Climate oscillation during the Quaternary has often been hypothesized to be an important factor in influencing the current geographical distribution and demographic history of plant species (Hewitt, 2004; Su \& Zhang, 2013). One widely utilized approach to comparing past and future distributions of plant species and determining the primary environment factors driving them is via ENM (e.g., Nabout, Magalhães, Ma, \& Da, 2016; Bai et al., 2017; Huang et al., 2017; Noulèkoun, Chude, Zenebe, \& Birhane, 2017; Swanti, Kusum, Dhruval, \& Rajkanti, 2018; Wei, Wang, Hou, Wang, \& Wu, 2018). Based on the neutral test, we found that the species did not expand its range during the Quaternary. Although these results were not statistically significant (Table 3), our ENMs, in general, show that the range of $P$. villosa contracted from the LGM to the present (Figure 6-7). Specifically, our models show that the range of $P$. villosa was the most extensive during the LIG period and included the northeast edge of the Qinghai-Tibet Plateau, Tarim Basin, Tianshan Mountains, Inner Mongolia Plateau, and the western regions of DaXinggan Ling. The range became limited to the Inner Mongolia Plateau, Ordos Plateau, and the Yinshan-Helanshan area during the LGM. The contraction of the range is likely the result of glaciation and climatic shifts within the Tianshan Mountains and Tarim Basin, where temperatures dropped significantly as glaciation developed on a large scale in the Northern Hemisphere during the early-Middle Pleistocene (Williams, Dunkerley, De, Dekker, Kershaw, \& Stokes, 1993; Yi et al., 2004; Shi, Cui, \& Su, 2005; Lehmkuhl \& Owen, 2005; Xu et al., 2010; Meng, Gao, Huang, \& Zhang, 2014). Nevertheless, it is surprising that the species range did not rebound as temperatures grew warmer following the LGM. This may be because of the onset of extreme aridity within the region during the Quaternary period, as this is widely-known to have played a significant role in determining the geographic distribution and evolutionary history of many plant species (Meng \& Zhang, 2011; Su, Zhang, \& Sanderson, 2011; Su \& Zhang, 2013). For example, in a previous study of Helianthemum songaricum (Cistaceae), which occurs in Northern China and adjacent desert areas of central Asia (Yang \& Gilbert, 2007), the worsening of the dry climate restricted the distribution range, and acceptable habitats for the species gradually became reduced and isolated ( $\mathrm{Su}$, Zhang, \& Sanderson, 2011). Besides, it needs to explain that AFLP dataset used in this manuscript do not reveal too many informative sites, so more markers should be selected to discuss the evolutionary history of $P$. villosa in the future.

\subsection{Germplasm conservation of $P$. villosa}

Psammochloa villosa is a dominant species in its desert habitat and sometimes the only herbaceous species occurring within its plant community. It helps to maintain a fragile desert ecosystem by preventing wind erosion, development of quicksand, and further desertification (Cai, 2016). While we found that it is a species of least concern (LC) based on EOO, we believe that it can only continue to perform its vital ecosystem services if its populations remain large and abundant.

This species may have great potential for sustainable utilization as a forage plant for livestock. The sand whips have relatively long inflorescences with large spikes that make it suitable for forage. Moreover, its adaptations to drought may make it a valuable source of genetic resources for molecular breeding of other crop and forage species as, presently, it is one of few forage species that can withstand the intensifying long-term drought conditions in northwest China. Developing a sustainable use strategy for $P$. villosa will also help to ensure its continued availability as a keystone species within desert communities of the Inner Mongolian Plateau and adjacent areas.

\section{Conflict of interest}


None declared.

\section{Author contributions}

Ting Lv:Investigation (equal); Conceptualization (equal); Data curation (equal); Methodology (lead); Formal analysis (equal); Writing-original draft (lead); Writing-review \& editing (equal). AJ Harris: Conceptualization (equal); Writing-original draft (lead); Writing-review \& editing (equal). Tao Liu: Investigation (equal); Formal analysis (equal); Methodology (supporting). Ruifang Liang: Data curation (equal); Formal analysis (equal); Methodology (supporting).Zilan Ma: Investigation (equal); Formal analysis (equal); Methodology (supporting). Yuping Liu: Conceptualization (equal); Formal analysis (equal); Methodology (supporting); Funding acquisition (lead); Writing-review \& editing (equal). Xu Su: Investigation (equal); Conceptualization (equal); Formal analysis (equal); Writing-original draft (supporting); Project administration (supporting); Supervision (lead); Writing-review \& editing (equal).

\section{Data accessibility}

All tables and figures supporting the results and conclusions were included in the article, except for the binary scoring of AFLP bands, which we have submitted to the Dryad Digital Repository (https://doi.org/10.5061/dryad.dbrv15f0v) and provided an available link for review at https://datadryad.org/stash/share/aepU6ms8Yp7kveC0mQTnYjxptp2GhAr3OUCteVtm5B4.

\section{ORCID}

Ting Lv: https://orcid.org/0000-0002-4751-8750

\section{Acknowledgements}

We greatly appreciate Dr. Jiabin Zou helping to improve an earlier draft of our manuscript. This work was financially supported by the National Natural Science Foundation of China (Grant Nos. 41761009 and 31800310), the Natural Science Foundation of Qinghai Province (Grant No. 2019-ZJ-7011), The Dawn of West China" Talent Training Program of the Chinese Academy of Sciences (2019-1-4) via grants made to XS.

\section{References}

An, Z. S., Kutzbach, J. E., Prell, W.L., \& Porter, S.C. (2001). Evolution of Asian monsoons and phased uplift of the Himalaya-Tibetan plateau since late Miocene times. Nature , 411(833), 62-66.

Bai, G. Q., Zhou, T., Zhang, X., Chen, X. D., Yang, J., Li, Z. H., \& Zhao, G. F. (2017). Genetic differentiation and population genetic structure of the Chinese endemic Dipteronia Oliv. revealed by cpDNA and AFLP Data. Forests , 8(11), 424.

Birky, C. M., Fuerst, P., \& Maruyama, T. (1989). Organelle gene diversity under migration, mutation, and drift: equilibrium expectations, approach to equilibrium, effects of heteroplasmic cells, and comparison to nuclear genes. Genetics, 121(3), 613-627.

Cai, X. X. (2016). Study on the genetic structure and clonal diversity of Psammophytes Leymus racemosus germplasm resources . Urumqi: Xinjiang Agricultural University.

Cai, X. X., Wumaierxiati, T. H., Dai, P. H., \& Jiaerken, Q. (2017). AFLP analysis on genetic diversity of Leymus racemosus in Xinjiang. Journal of Arid Land Resources and Environment, 31(9), 130-134.

Comes, H. P., \& Kadereit, J. W. (1998). The effect of Quatemary climatic changes on plant distribution and evolution. Trends in Plant Science, 3(11), 432-438.

Deng, L., Zhang, Z., \& Shangguan, Z. (2014). Long-term fencing effects on plant diversity and soil properties in China. Soil and Tillage Research, 137, 7-15. 
Dong, M., \& Alaten, B. (1999). Clonal plasticity in response to rhizome severing and heterogeneous resource supply in the rhizomatous grassPsammochloa villosa in an Inner Mongolian dune, China.Plant Ecology, $141,53-58$.

Doyle, J. J., \& Doyle, J. L. (1987). A rapid DNA isolation procedure for small quantities of fresh leaf material. Phytochemical Bulletin, 19, 11-15.

Dupanloup, I., Schneider, S., \& Excoffier, L. (2002). A simulated annealing approach to define the genetic structure of populations. Molecular Ecology , 11(12), 2571-2581.

Elias, S. A. (2013). The Quaternary . Reference Module in Earth Systems and Environmental Sciences.

El-Tayeh, N. A., Galal, H. K., Soliman, M. I., \& Zaki, H. (2020). Association of morphological, ecological, and genetic diversity ofAerva javanica populations growing in the eastern desert of Egypt. Agronomy , 10(3), 402-419.

Eriksson, O., \& Bremer, B. (1993). Genet dynamics of the clonal plantRubus saxatilis . Journal of Ecology , 81(3), 533-542.

Evanno, G., Regnaut, S., \& Goudet, J. (2005). Detecting the number of clusters of individuals using the software STRUCTURE: a simulation study. Molecular Ecology , 14(8), 2611-2620.

Excoffier, L., Smouse, P. E., \& Quattro, J. M. (1992). Analysis of molecular variance inferred from metric distances among DNA haplotypes: Application to human mitochondrial DNA restriction data.Genetics , 131(2), 479-491.

Excoffier, L., Laval, G., \& Schneider, S. (2005). Arlequin ver. 3.0: An integrated software package for population genetics data analysis. Evolutionary Bioinformatics Online , 1(47), 47-50.

Falush, D., Stephens, M., \& Pritchard, J. K. (2007). Inference of population structure using multilocus genotype data: Dominant markers and null alleles. Molecular Ecology Notes , 7(4), 574-578.

Ge, X. J., Yu, Y., Yuan, Y. M., Huang, H. W., \& Yan, C. (2005). Genetic diversity and geographic differentiation in endangered Ammopiptanthus (Leguminosae) populations in desert regions of northwest China as revealed by ISSR analysis. Annals of Botany , 95(5), 843-851.

Ge, X. J., Hwang, C. C., Liu, Z. H., Huang, C. C., Huang, W. H., Huang, K. H., Wang, W. K., \& Chiang, T. Y. (2011). Conservation genetics and phylogeography of endangered and endemic shrub Tetraena mongolica(Zygophyllaceae) in Inner Mongolia, China. BMC Genetics , 12(1), 1-12.

Gong, L., Song, X., Li, M., Guo, W. L., Hu, L. J., Tian, Q., Yang, Y. F., Zhang, Y. F., Zhong, X. F., Wang, D. L., \& Liu, B. (2007). Extent and pattern of genetic differentiation within and between phenotypic populations of Leymus chinensis (Poaceae) revealed by AFLP analysis. Canadian Journal of Botany, 85(9), 813-821.

Hamrick, J. L., \& Godt, M. J. W. (1989). Allozyme diversity in plant species // Brown ADH, Clegg MT, Kahler AL, et al. Plant population genetics, breeding and genetic resource. Sunderland: Sinauer Press, 44-619.

Hamrick, J. L., \& Godt, M. J. W. (1996). Effects of life history traits on genetic diversity in plant species. Philosophical Transactions of the Royal Society of London Series B-biological Sciences B , 351(1345), 12911298.

Hanafi, A., \& Jauffret, S. (2008). Are long-term vegetation dynamics useful in monitoring and assessing desertification processes in the arid steppe, southern Tunisia. Journal of Arid Environments , 72(4), 57-572.

Hao, C. Y. (2005). Studies on population ecology and genetic diversity of Heptacodium miconioides . Hangzhou: Zhejiang Normal University. 
Helena, K., \& Mikko, K. (1996). Genetic diversity and population structure in the outcrossing populations of Equisetum arvense andE. hyemale (Equisetaceae). American Journal of Botany, 83(1), 58-62.

Hewitt, G. (2000). The genetic legacy of the Quaternary ice ages.Nature , 405(6789), 907-913.

Hewitt, G. M. (2004). Genetic consequences of climatic oscillations in the Quaternary. Philosophical Transactions of the Royal Society B: Biological Sciences, 359(1442), 183-195.

Hijmans, R. J., Cameron, S. E., Parra, J. L., Jones, P. G., \& Jarvis, A. (2005). Very high resolution interpolated climate surfaces for global land areas. International Journal of Climatology, 25(15), 1965-1978.

Huang, J., Li, G., Li, J., Zhang, X., Yan, M., \& Du, S. (2017). Projecting the range shifts in climatically suitable habitat for Chinese sea buckthorn under climate change scenarios. Forests , 9(1), 9.

Huang, Z. Y., Wu, H., \& Hu, Z. H. (1995). An anatomical study on xeromorphic structures of the psammophytes in Xinjiang. Acta Botanica Boreali-Occidentalia Sinica , 15(), 56-61.

Huang, Z. Y., Wu, H., \& Hu, Z. H. (1997). The structures of 30 species of psammophytes and their adaptation to the sandy desert environment in Xinjiang. Acta Phytoecologica Sinica, 21(6), 521-530.

Huang, Z. Y. (2003). Adaptation strategies of seed dormancy and germination of Psammochloa villosa, a sand dune grass inhabiting Ordos Plateau, China. Acta Botanica Boreali-Occidentalia Sinica , 23(7), 1128-1133.

Huang, Z. Y., Dong, M., \& Gutterman, Y. (2004). Factors influencing seed dormancy and germination in sand, and seedling survival under desiccation, of Psammochloa villosa (Poaceae), inhabiting the moving sand dunes of Ordos, China. Plant and Soil , 259(1-2), 231-241.

Hubisz, M. J., Falush, D., Stephens, M., \& Pritchard, J. K. (2009). Inferring weak population structure with the assistance of sample group information. Molecular Ecology Resources , 9(5), 1322-1332.

Huson, D. H., \& Bryant, D. (2006). Application of phylogenetic networks in evolutionary studies. Molecular Biology and Evolution, 23(2), 254-267.

IUCN. 2001. IUCN Red List Categories and Criteria: Version 3.1. IUCN Species Survival Commission, Gland . Available at www.iucnredlist.org/technical-documents/categories-and-criteria/2001-categoriescriteria. [accessed 07 March 2014].

IUCN. 2020. The IUCN Red List of Threatened Species. Version 2020-2 . https://www.iucnredlist.org.

Jia, D. R., Abbott, R. J., Liu, T. L., Mao, K. S., Bartish, I. V., \& Liu, J. Q. (2012). Out of the Qinghai-Tibet Plateau: evidence for the origin and dispersal of Eurasian temperate plants from a phylogeographic study of Hippophae rhamnoides (Elaeagnaceae). New Phytologist , 194(4), 1123-1133.

Jiang, D. B., Lang, X. M., Tian, Z. P., \& Guo, D. L. (2011). Last glacial maximum climate over China from PMIP simulations.Palaeogeography, Palaeoclimatology, Palaeoecology , 309(3-4), 347-357.

Kimura, M., \& Crow, J. F. (1964). The number of alleles that can be maintained in a finite population. Genetics , 49, 725-738.

Kuo, P. C. (1987). Flora Reipublicae Popularis Sinicae (Tomus 9) . Beijing: Science Press, 309.

Lachenaud, O., Droissart, V., Dessein, S., Stevart, T., Simo, M., Lemaire, B., Taedoumg, H., \& Sonke, B. (2013). New records for the flora of Cameroon, including a new species of Psychotria(Rubiaceae) and range extensions for some rare species. Plant Ecology \& Evolution , 146(1), 121-133.

Lehmkuhl, F., \& Owen, L. A. (2005). Late Quaternary glaciation of Tibet and the bordering mountains: a review. Boreas, 34(2), 87-100.

Lewontin, R. C. (1972). Testing the theory of natural selection.Nature, 236(5343), 181-182. 
Li, A., \& Ge, S. (2001). Genetic variation and clonal diversity of Psammochloa villosa (Poaceae) detected by ISSR markers. Annals of Botany , 87(5), 585-590.

Li, M., Qi, X., Yuyama, N. N., Wang, Y. W., Sun, Y., Mao, P. S., \& Cai, H. W. (2015). Synteny between Zoysia japonica Steud. andOryza sativa L. based on RFLP, CISP and PLUG markers. Genetic Resources and Crop Evolution, 62(6), 853-862.

Li, Q. E., Guo, X., Niu, J. F., Duojie, D. Z., Li, X. J., Opgenoorth, L., \& Zou, J. B. (2020). Molecular phylogeography and evolutionary history of the endemic species Corydalis hendersonii(Papaveraceae) on the Tibetan Plateau inferred from chloroplast DNA and ITS sequence variation. Frontiers in Plant Science, $11,436$.

Li, X. Y., Liu, L. Y., \& Wang, J. H. (2004). Wind tunnel simulation of aeolian sandy soil erodibility under human disturbance.Geomorphology , 59(1-4), 3-11.

Liu, J. Q., Sun, Y. S., Ge, X. J., Gao, L. M., \& Qiu, Y. X. (2012). Phylogeographic studies of plants in China: advances in the past and directions in the future. Journal of Systematics and Evolution, 50(4), $267-275$.

Liu, Y. P., Su, X., He, Y. H., Han, L. M., Huang, Y. Y., \& Wang, Z. Z. (2015). Evolutionary history of Orinus thoroldii (Poaceae), endemic to the western Qinghai-Tibetan Plateau in China.Biochemical Systematics and Ecology, 59, 159-167.

Liu, Y. P., Ren, Z. M., Harris, A. J., Peterson, P. M., Wen, J., \& Su, X. (2018). Phylogeography of Orinus (Poaceae), a dominant grass genus on the Qinghai-Tibet Plateau. Botanical Journal of the Linnean Society , 186(2), 202-223.

Liu, Y. P., Harris, A. J., Gao, Q. B., Su, X., \& Ren, Z. M. (2019). A population genetics perspective on the evolutionary histories of three clonal, endemic, and dominant grass species of the Qinghai-Tibet Plateau: Orinus (Poaceae). Ecology and Evolution, 9(10), 6014-6037.

Liu, Y. X. (1985). Flora in Desertis Reipublicae Populorum Sinarum (Tomus 1) . Beijing: Science Press, 34.

Liu, Y. X. (1995). A study on origin and formation of the Chinese desert flora. Acta Phytotaxonomica Sinica , 33, 131-143.

Loveless, M. D., \& Hamrick, J. L. (1984). Ecological determinants of genetic structure in plant populations. Annual Review of Ecology and Systematics , 15, 65-95.

Lu, S. L. (1987). Psammochloa Hitchc. Kuo P C. Flora Reipublicae Popularis Sinicae (Tomus 9) . Beijing: Science Press, 309.

Lv, T., Liu, Y. P., Zhou, Y. H., Liu, T., Zhang, X. Y., \& Su, X. (2018). Micromorphological characteristics of leaf epidermis and ecological adaptation of Psammochloa villosa, a desert plant from the Inner Mongolian Plateau. Bulletin of Botanical Research , 38(3), 330-337.

Ma, K. P., Qian, Y. Q., \& Wang, C. (1994). Principles and methods of biodiversity research . Beijing: Science and Technology of China Press, 1:12.

Ma, K. W. (1991). Land Dictionary. Changchun: Changchun Publishing House.

Ma, S. M., Zhang, M. L., \& Sanderson, S. C. (2012). Phylogeography of the rare Gymnocarpos przewalskii (Caryophyllaceae): indications of multiple glacial refugia in north-western China. Australian Journal of Botany , 60(1), 20-31.

Ma, Y. Q. (1994). Flora Innermongolica (Tomus 5). 2nd ed . Hohhot: Inner Mongolia People's Publishing House, 115-152. 
Mantel, N. (1967). Detection of disease, clustering and generalized regression approach. Cancer Resources , 27, 209-220.

McDermott, J. M., \& McDonald, B. A. (1993). Gene flow in plant pathosystems. Annual Review of Phytopathology , 31(1), 353-373.

Meng, H. H., \& Zhang, M. L. (2011). Phylogeography of Lagochilus ilicifolius (Lamiaceae) in relation to Quaternary climatic oscillation and aridification in Northern China. Biochemical Systematics and Ecology, 39(4-6), 787-796.

Meng, H. H., Gao, X. Y., Huang, J. F., \& Zhang, M. L. (2014). Plant phylogeography in arid northwest China: retrospectives and perspectives. Journal of Systematics and Evolution, 53(1), 33-46.

Merklinger, F. F., Zheng, Y., Luebert, F., Harpke, D., Bohnert, T., Stoll, A., Koch, M. A., Blattner, F. R., Wiehe, T., \& Quandt, D. (2019). Population genomics of Tillandsia landbeckii reveals unbalanced genetic diversity and founder effects in the Atacama Desert.Global and Planetary Change, 184.

Moat, J. (2007). Conservation assessment tools extension for ArcView 3.x, version 1.2. GIS Unit, Royal Botanic Gardens, Kew.

Nabout, J. C., Magalhaes, M. R., Ma, D. A. G., \& Da, C. H. (2016). The impact of global climate change on the geographic distribution and sustainable harvest of Hancornia speciosa Gomes (Apocynaceae) in Brazil. Environmental Management, 57(4), 814-821.

Nei, M. (1973). Analysis of gene diversity in subdivided populations.Proceedings of National Academy of Sciences of the United States of America, 70, 3321-3323.

Noulekoun, F., Chude, S., Zenebe, A., \& Birhane, E. (2017). Climate change impacts on Faidherbia albida (Delile) A. Chev. distribution in dry lands of Ethiopia. African Journal of Ecology , 55, 233-243.

Pan, B. R. (2006). Life interpretation in the desert - the Psammophytes. Forest and human , 6, 70-73.

Peakall, R., \& Smouse, P. (2012). GenAIEx 6.5: Genetic analysis in Excel: Population genetic software for teaching and research - an update. Bioinformatics , 28, 2537-2539.

Peters, D. P. C., Yao, J., Sala, O. E., \& Anderson, J. P. (2012). Directional climate change and potential reversal of desertification in arid and semiarid ecosystems. Global Change Biology, 18(1), 151-163.

Peterson, A. T., \& Nakazawa, Y. (2008). Environmental data sets matter in ecological niche modeling: an example with Solenopsis invictaand Solenopsis richteri . Global Ecology and Biogeography, 17, 135-144.

Phillips, S. J., Anderson, R. P., \& Schapire, R. E. (2006). Maximum entropy modeling of species geographic distributions. Ecological Modeling , 190(3-4), 231-259.

Phillips, S. J., \& Dudik, M. (2008). Modeling of species distributions with MaxEnt: new extensions and a comprehensive evaluation.Ecography, 31(2), 161-175.

Pillans, B., \& Gibbard, P. (2012). The Quaternary Period. The Geologic Time Scale , 1, 979-1010.

Pritchard, J. K., Stephens, M., \& Donnelly, P. (2000). Inference of population structure using multilocus genotype data. Genetics, 155, 945-959.

Qiu, Y. X., Fu, C. X., \& Comes, H. P. (2011). Plant molecular phylogeography in China and adjacent regions: tracing the genetic imprints of Quaternary climate and environmental change in the world's most diverse temperate flora. Molecular Phylogenetics and Evolution, 59(1), 225-244.

Rohlf, F. J. (1997). NTSYS-pc 2.1 . Numerical taxonomy and multivariate analysis system. Exeter, UK.

Schoener, T. W. (1968). The Anolis Lizards of Bimini: resource partitioning in a complexfauna. Ecology , 49, 704-726. 
Shackleton, N. J., \& Opdyke, N. D. (1973). Oxygen isotope and palaeomagnetic stratigraphy of Equatorial Pacific core V28-238: oxygen isotope temperatures and ice volumes on a $10^{5}$ year and $10^{6}$ year scale. Quaternary Research , 3(1), 39-55.

Shi, Y. F., Cui, Z. J., \& Su, Z. (2005). The quaternary glaciations and environmental variations in China. Shijiazhuang: Hebei Science and Technology Publishing House, 450-499.

Shimizu, T., Hatanaka, Y., Zentoh, H., Yashima, T., Kinoshita, E., \& Watano, Y. (1998). The role of sexual and clonal reproduction in maintaining population in Fritillaria camtschatcensis (L.) Ker-Gawl. (Liliaceae). Ecological Research , 13(1), 27-39.

Shuyskaya, E., Toderich, K., Gismatullina, L., Rajabov, T., \& Khohlov, S. (2017). Genetic diversity of two annual Salsola species (Chenopodiaceae) among habitat types in desert plant communities.Biologia , 72(3), 267-276.

Silva, L. N. D., Essi, L., Welker, C. A. D., \& de, Souza-Chies, T. T. (2016). Assessing the genetic diversity and population structure of the endangered Chascolytrum bulbosum (Poaceae, Poeae) using AFLP markers. Biochemical Systematics and Ecology, 68, 236-242.

Sim, S., Chang, T., Curley, J., Warnke, S. E., Barker, R. E., \& Jung, G. (2005). Chromosomal rearrangements differentiating the ryegrass genome from the Triticeae, oat, and rice genomes using common heterologous RFLP robes. Theoretical and Applied Genetics , 110, 1011-1019.

Slatkin, M. (1987). Gene flow and the geographic structure of natural populations. Science, 236(4803), 787-792.

State Forestry Administration. 2015. Bulletin of desertification and sandification state of China . Beijing: State Forestry Administration.

$\mathrm{Su}$, Y. (2013). Analysis on the population genetic diversity of desert super-xerophytic shrub Reaumuria soongorica . Chengdu: University of Electronic Science and Technology of China.

Su, Z. H., Zhang, M. L., \& Sanderson, S. C. (2011). Chloroplast phylogeography of Helianthemum songaricum (Cistaceae) from northwestern China: implications for preservation of genetic diversity. Conservation Genetics , 12(6), 1525-1537.

Su, Z. H., \& Zhang, M. L. (2013). Evolutionary response to Quaternary climate aridification and oscillations in north-western China revealed by chloroplast phylogeography of the desert shrub Nitraria sphaerocarpa (Nitrariaceae). Biological Journal of the Linnean Society, 109(4), 757-770.

Swanti, S., Kusum, A., Dhruval, B., \& Rajkanti, K. (2018). Modeling habitat suitability of Perilla frutescens with MaxEnt in Uttarakhand - a conservation approach. Journal of Applied Research on Medicinal $\mathcal{E}^{3}$ Aromatic Plants .

Swets, J. A. (1988). Measuring the accuracy of diagnostic systems.Science , 240(4857), 1285-1293.

Tian, B., Liu, R. R., Wang, L. Y., Qiu, Q., Chen, K. M., \& Liu, J. Q. (2009). Phylogeographic analyses suggest that a deciduous species (Ostryopsis davidiana Decne. Betulaceae) survived in Northern China during the last glacial maximum. Journal of Biogeography , 36(11), 2148-2155.

Van, Vuuren, D. P., Edmonds, J., Kainuma, M., Riahi, K., Thonmson, A., Hibbard, K., Hurtt, G. C., Kram, T., Krey, V., Lamarque, J. F., Masui, T., Meinshausen, M., Nakicenovic, N., Smith, S. J., \& Rose, S. K. (2011). The representative concentration pathways: an overview.Climatic Change , 109(1-2), 5-31.

Vavilov, N. I. (1926). Studies on the origin of cultivated plants . Leningrad: Institute of Applied Botany and Plant Breeding, State Press.

Velzen, R. V., \& Wieringa, J. J. (2014). Rinorea calcicola(Violaceae), an endangered new species from south-eastern Gabon.Phytotaxa, 167(3), 267-275. 
Vos, P., Hogers, R., Bleeker, M., Reijans, M., Lee, T. V., Hornes, M., Friters, A., Pot, J., Paleman, J., Kuiper, M., \& Zabeau, M. (1995). AFLP : a new technique for DNA fingerprinting. Nucleic Acids Research , 23, 4407-4414.

Wang, H. X., \& Hu, Z. A. (1996). Plant breeding system, genetic structure and conservation of genetic diversity. Chinese Biodiversity , 4(2), 92-96.

Wang, J., \& Zhou, J. (2015). Quantitative assessment of soil erosion in areas under grain for green project in Loess Plateau of Northern Shaanxi Province based on GIS and RS. Bulletin of Soil and Water Conservation , 35(1), 220-229.

Wang, K. Q., Ge, S., \& Dong, M. (1999). Allozyme variance and clonal diversity in the rhizomatous grass Psammochloa villosa(Gramineae). Acta Botanica Sinica , 41(5), 537-540.

Wang, L. Y., Abbott, R. J., Zhang, W., Chen, P., Wang, Y. J., \& Liu, J. Q. (2009). History and evolution of alpine plants endemic to the Qinghai-Tibetan Plateau: Aconitum gymnandrum (Ranunculaceae).Molecular Ecology , 18(4), 709-721.

Wang, S. X., Wang, F., Liu, C. B., Yang, Z. Y., \& Chen, X. (2008). Application of DNA molecular markers in endangered species conservation. Chinese Journal Ecology , 27(2), 250-256.

Wang, W. C., \& Warnock, M. J. (2001). Flora of China (vol. 6) . Beijing: Science Press and Missouri Botanical Garden Press, 243.

Wang, Y. H., Dong, M., Yu, F. H., Jiang, H., Yu, S. Q., Lin, X. Q., \& He, W. M. (2011). Mechanical shaking and soil water affect the growth ofPsammochloa villosa in the Mu Us Sandland. Journal of Arid Environments , 75(10), 974-977.

Warren, D. L., Glor, R. E., \& Turelli, M. (2008). Environmental niche equivalency versus conservatism: quantitative approaches to niche evolution. Evolution , 62(11), 2868-2883.

Warren, D. L., Glor, R. E., \& Turelli, M. (2010). ENMTools: a toolbox for comparative studies of environmental niche models.Echography , 33(3), 607-611.

Wei, B., Wang, R., Hou, K., Wang, X., \& Wu, W. (2018). Predicting the current and future cultivation regions of Carthamus tinctorius L. using MaxEnt model under climate change in China. Global Ecology and Conservation, 16, e00477.

Wei, W., Wang, B., \& Niu, X. (2020). Soil erosion reduction by grain for green project in desertification areas of Northern China.Forests, 11(4), 473.

Wen, Y. F., Han, W. J., \& Wu, S. (2010). Plant genetic diversity and its influencing factors. Journal of Central South University of Forestry \& Technology , 30(12), 80-87.

Williams, M. A. J, Dunkerley, D. L., De, Dekker, P., Kershaw, A. P., \& Stokes, T. (1993). Quaternary environments . London: Edward Arnold, 87-112.

Wright, S. (1978). Evolution and the genetics of populations (Vol 4). Chicago: University of Chicago Press.

Wu, G. J. (2002). The maximum glaciation and desert expansion in China during MIS16. Glaciol Geocryol , 24, 544-549.

Wu, X., Wang, F., \& An, Z. S. (1992). The phase and height of the Tibetan Plateau rise in late Cenozoic . In: Liu, D. S., An, Z. S. (Eds.), Loess Quaternary Geology Global Changes, vol. 3 . Beijing: Scientific Publishing House,1-13.

Wu, Z. L., \& Phillips, S. M. (2006). Psammochloa (Poaceae). In: Wu, Z. Y., Raven, P. H., eds. Flora of China (vol. 22) . Beijing: Science Press and Missouri Botanical Garden Press, 192. 
Xia, L. Q., Li, J. Q., \& Li, W. (2002). Genetic diversity of clonal plant. Chinese Bulletin of Botany , 19(4), 425-431.

Xu, X. K., Kleidon, A., Miller, L., Wang, S. Q., Wang, L. Q., \& Dong, G. C. (2010). Late Quaternary glaciation in the Tianshan and implications for palaeoclimatic change: a review. Boreas , 39(2), 215-232.

Xu, Z., \& Zhang, M. L. (2015). Phylogeography of the arid shrub Atraphaxis frutescens (Polygonaceae) in northwestern China: evidence from cpDNA sequences. Journal of Heredity , 106(2), 184-195.

Yang, D., Fang, X. M., Dong, G. R., Peng, Z. C., \& Li, J. J. (2006). Aeolian deposit evidence for formation and evolution of the Tengger desert in the north of China since early Pleistocene. Marine Geology $\mathcal{E}^{3}$ Quaternary Geology , 26, 93-100.

Yang, Q. E., \& Gilbert, M. G. (2007). Flora of China (vol. 13) . Beijing: Science Press and Missouri Botanical Garden Press, 70.

Yeh, F., Yang, R., \& Boyle, T. (1999). POPGENE: Microsoft Windows-based freeware for population genetic analysis. Version 1.31. Edmonton: University of Alberta.

Yi, C. L., Liu, K. X., Cui, Z. J., Jiao, K. Q., Yao, T. D., \& He, Y. Q. (2004). AMS radiocarbon dating of late Quaternary glacial landforms, source of the Urumqi River, Tian Shan - a pilot study of $14 \mathrm{C}$ dating on inorganic carbon. Quaternary International , 121(1), 99-107.

Zhang, C. L., Yang, X. P., Zhao, W. D., Zhang, X. Q., Sun, M., Wang, X., Wu, W. D., Xiong, Y., \& Ma, X. (2017). AFLP analysis of genetic diversity of wide Dactylis glomerata germplasm. Acta Botanica Boreali-Occidentalia Sinica, 37(9), 1711-1719.

Zhang, C. Q., \& Jia, J. Z. (2002). Studies on the primers screening for AFLP fingerprints of Oryza sativa . Scientia Agricultura Sinica, 35(7), 733-737.

Zhang, H. X., \& Zhang, M. L. (2012). Genetic structure of theDelphinium naviculare species group tracks Pleistocene climatic oscillations in the Tianshan Mountains, arid Central Asia.Palaeogeography, Palaeoclimatology, Palaeoecology, 353-355, 93-103.

Zhang, H. X., Zhang, M. L., \& Williams, D. M. (2014). Genetic evidence and species distribution modelling reveal the response of Larix sibirica and its related species to Quaternary climatic and ancient historical events. Biochemical Systematics and Ecology, 54, 316-325.

Zhang, Y. J., He, X. L., Zhao, L. L., Zhang, J., \& Xu, W. (2017). Dynamics of arbuscular mycorrhizal fungi and glomalin underPsammochloa villosa along a typical dune in desert, North China.Symbiosis , 73, $145-153$.

Zhen, Z. L. (2010). Studies on genetic diversity and construction of fingerprinting of Magnolia officinalis . Fuzhou: Fujian Agricultural and Forestry University.

Zhou, Y. Y., Feng, J. Z., Yuan, F., \& Jing, Y. X. (2011). A review on genetic diversity of psammophytes in China. Journal of Minzu University of China (Natural Sciences Edition ), 20(3), 5-11.

Zhu, Y. J., Dong, M., \& Huang, Z. Y. (2005). Effects of sand burial and seed size on seed cermination and seedling emergence of Psammochloa villosa . Acta Phytoecologica Sinica , 29(5), 730-739.

Table 1 Adapters and primer combination sequences used in the present study

\begin{tabular}{lll}
\hline Primer & Name & Sequence \\
\hline Adapters & Adapters & Adapters \\
E-L & EcoR I-adapter & 5'-CTCGTAGACTGCGTACC-3' \\
E-R & EcoR I-adapter & 5'-AATTGGTACGCAGTCTAC-3' \\
M-L & Mse I-adapter & 5'-GACGATGAGTCCTGAG-3'
\end{tabular}




\begin{tabular}{lll}
\hline Primer & Name & Sequence \\
\hline M-R & Mse I-adapter & 5'-TACTCAGGACTCAT-3' \\
Preamplification primer & Preamplification primer & Preamplification primer \\
P01 & EcoR I & 5'-GACTGCGTACCAATTCA-3' \\
P02 & Mse I & 5'-GATGAGTCCTGAGTAAC-3' \\
Selective amplification primer & Selective amplification primer & Selective amplification primer \\
A-1 & EcoR I-AAC & 5'-GACTGCGTACCAATTCAAC-3' \\
& $M s e$ I-CAA & 5'-GATGAGTCCTGAGTAACAA-3' \\
A-2 & EcoR I-AAG & 5'-GACTGCGTACCAATTCAAG-3' \\
& Mse I-CAC & 5'-GATGAGTCCTGAGTAACAC-3' \\
A-3 & EcoR I-ACA & 5'-GACTGCGTACCAATTCACA-3' \\
& Ese I-CAG & 5'-GATGAGTCCTGAGTAACAG-3' \\
B-1 & EcoR I-ACT & 5'-GACTGCGTACCAATTCACT-3' \\
& Mse I-CAT & 5'-GATGAGTCCTGAGTAACAT-3' \\
B-2 & EcoR I-ACC & 5'-GACTGCGTACCAATTCACC-3', \\
& $M s e$ I-CTA & 5'-GATGAGTCCTGAGTAACTA-3' \\
C-1 & EcoR I-ACG & 5'-GACTGCGTACCAATTCACG-3' \\
& $M s e$ I-CTC & 5'-GATGAGTCCTGAGTAACTC-3' \\
D-1 & EcoR I-AGC & 5'-GACTGCGTACCAATTCAGC-3' \\
& $M s e$ I-CTG & 5'-GATGAGTCCTGAGTAACTG-3' \\
D-2 & EcoR I-AGG & 5'-GACTGCGTACCAATTCAGG-3' \\
& $M s e$ I-CTT & 5'-GATGAGTCCTGAGTAACTT-3' \\
\hline
\end{tabular}

Table 2 Summary statistics for eight selective primer combinations of amplified fragment length polymorphism (AFLP) in the present study

\begin{tabular}{|c|c|c|c|c|c|c|c|}
\hline Selective nuclear & Polymorphism band & Amplification band & PPL $(\%)$ & Size range (bp) & $\mathrm{Na}$ & $\mathrm{Ne}$ & $\bar{h}$ \\
\hline E-AAC/M-CAA & 201 & 216 & 93.06 & $69.5-501.5$ & 1.9950 & 1.3397 & 0.2118 \\
\hline E-AAG/M-CAC & 199 & 216 & 92.13 & $69.5-501.5$ & 2.0000 & 1.3261 & 0.2030 \\
\hline $\mathrm{E}-\mathrm{ACA} / \mathrm{M}-\mathrm{CAG}$ & 206 & 216 & 95.37 & $69.5-501.5$ & 2.0000 & 1.3201 & 0.2079 \\
\hline $\mathrm{E}-\mathrm{ACT} / \mathrm{M}-\mathrm{CAT}$ & 211 & 216 & 97.69 & $69.5-501.5$ & 2.0000 & 1.3259 & 0.2084 \\
\hline E-ACC/M-CTA & 211 & 216 & 97.69 & $69.5-501.5$ & 2.0000 & 1.3060 & 0.1988 \\
\hline E-ACG/M-CTC & 214 & 216 & 99.07 & $69.5-501.5$ & 2.0000 & 1.2898 & 0.1926 \\
\hline E-AGC/M-CTG & 199 & 216 & 92.13 & $69.5-501.5$ & 2.0000 & 1.3445 & 0.2131 \\
\hline E-AGG/M-CTT & 213 & 216 & 98.61 & $69.5-501.5$ & 2.0000 & 1.3311 & 0.2091 \\
\hline Total & 1654 & 1728 & - & - & - & - & \\
\hline Average & 207 & 216 & 95.72 & - & 1.9994 & 1.3229 & 0.2056 \\
\hline
\end{tabular}

Note. PPL, percentage of polymorphic loci; $N$ a, observed number of alleles; $N$ e, effective number of alleles; $h$, Nei's genetic diversity; $I$, Shannon's information index. $H$ t, total gene diversity; $H$ s, the average gene diversity within populations; $G_{\mathrm{ST}}$, the genetic differentiation between populations; $N \mathrm{~m}$, gene flow.

Table 3 Genetic diversity, differentiation parameters, and neutrality test for 43 populations of $P$. villosa in the present study

\begin{tabular}{llllllllll}
\hline Population group & $N \mathrm{a}$ & $N \mathrm{e}$ & $h$ & $I$ & $H \mathrm{t}$ & $H \mathrm{~s}$ & $G_{\mathrm{ST}}$ & $N \mathrm{~m}$ & Fu's $F s(P$-Value $)$ \\
\hline Populations of Group1 (1-12) & 1.7645 & 1.2681 & 0.1668 & 0.2656 & 0.1668 & 0.1102 & 0.3402 & 0.9996 & $3.2491(0.5701)$ \\
Populations of Group2 (13-43) & 1.9710 & 1.3001 & 0.1921 & 0.3116 & 0.1918 & 0.1083 & 0.4349 & 0.6605 & $3.3578(0.5738)$
\end{tabular}




\begin{tabular}{llllllllll}
\hline Population group & $N \mathrm{a}$ & $N \mathrm{e}$ & $h$ & $I$ & $H \mathrm{t}$ & $H \mathrm{~s}$ & $G_{\mathrm{ST}}$ & $N \mathrm{~m}$ & Fu's $F s(P$-Value $)$ \\
\hline All populations & 1.9994 & 1.3229 & 0.2056 & 0.3316 & 0.2052 & 0.1088 & 0.4689 & 0.5761 & $3.3274(0.5702)$ \\
\hline
\end{tabular}

$N$ a, observed number of alleles; $N$ e, effective number of alleles; $h$, Nei's genetic diversity; $I$, Shannon's information index. $H \mathrm{t}$, total gene diversity; $H \mathrm{~s}$, the average gene diversity within populations; $G_{\mathrm{ST}}$, the genetic differentiation between populations; $N \mathrm{~m}$, gene flow.

Table 4 Results of analyses of molecular variance (AMOVAs) based on amplified fragment length polymorphism markers for $P$. villosa

\begin{tabular}{lllllll}
\hline Grouping & Source of variation & $d f$ & $\mathrm{SS}$ & $\mathrm{VC}$ & Percent variation $(\%)$ & Fixatio \\
\hline Total populations & Among populations & 42 & 20586.257 & 73.45887 & $35.84 \%$ & $F_{\mathrm{ST}}=0$. \\
& Within populations & 167 & 21960.467 & 131.49980 & $64.16 \%$ & \\
& Total & 209 & 42546.724 & 204.95867 & & $F_{\mathrm{CT}}=0$ \\
SAMOVA groups & Among groups & 1 & 4707.100 & $50.33831 \mathrm{Va}$ & $21.49 \%$ & $F_{\mathrm{SC}}=0$ \\
& Among populations within groups & 41 & 15879.157 & $52.41736 \mathrm{Vb}$ & $22.38 \%$ & $F_{\mathrm{ST}}=0$. \\
& Within populations & 167 & 21960.467 & $131.49980 \mathrm{Vc}$ & $56.14 \%$ & \\
& Total & 209 & 42546.724 & 234.25546 & & \\
\hline
\end{tabular}

Note. $d f$, degrees of freedom; SS, sum of squares; VC, variance components; $F{ }_{\mathrm{CT}}$, variance among groups relative to total variance; $F \mathrm{SC}$, variance among populations within groups; $F$ sT, variance among populations; Significant level:** $p<0.001$.

Table 5 Environmental variables used for modeling and percent contribution of $P$. villosa

\begin{tabular}{lll}
\hline Code & Environment variable & Contribution/\% \\
\hline Alt & Altitude & 40 \\
Bio 7 & Temperature annual range (bio5-bio6) & 17.2 \\
Bio 18 & Precipitation of warmest quarter & 16.7 \\
Slop & Slope & 8.3 \\
Bio 19 & Precipitation of coldest quarter & 7.2 \\
Bio 15 & Precipitation seasonality (coefficient of variation) & 4.2 \\
Bio 6 & Min temperature of coldest month & 2.4 \\
Asp & Aspect & 1.7 \\
Bio 5 & Max temperature of warmest month & 1 \\
Bio 2 & Mean diurnal range (mean of monthly (max temp-min temp)) & 0.9 \\
Bio 3 & Isothermality (Bio 2/Bio 7) (×100) & 0.3 \\
\hline
\end{tabular}

Table 6 Prediction of potential suitable distribution areas of $P$. villosa in different periods

\begin{tabular}{lllll}
\hline Period & Prediction area $\left(\times 10^{4} \mathrm{~km}^{2}\right)$ & Prediction area $\left(\times 10^{4} \mathrm{~km}^{2}\right)$ & Prediction area $\left(\times 10^{4} \mathrm{~km}^{2}\right)$ & Prediction area $(\times 10$ \\
\hline & Unsuitable habitat & Poorly suitable habitat & Moderately suitable habitat & Highly suitable habi \\
LIG & 532.4994 & 85.2601 & 54.3909 & 282.0408 \\
LGM & 724.5804 & 111.8953 & 45.7149 & 74.2954 \\
Present & 845.8872 & 43.8207 & 30.2673 & 37.1570 \\
2050s-2.6 & 804.7547 & 65.9706 & 25.4776 & 60.2943 \\
2050s-8.5 & 793.9596 & 72.6263 & 29.3144 & 60.5905
\end{tabular}




\begin{tabular}{lllll}
\hline Period & Prediction area $\left(\times 10^{4} \mathrm{~km}^{2}\right)$ & Prediction area $\left(\times 10^{4} \mathrm{~km}^{2}\right)$ & Prediction area $\left(\times 10^{4} \mathrm{~km}^{2}\right)$ & Prediction area $(\times 1$ \\
\hline $2070 \mathrm{~s}-2.6$ & 804.7547 & 65.9706 & 25.4776 & 60.2943 \\
$2070 \mathrm{~s}-8.5$ & 710.9724 & 112.0121 & 47.4650 & 86.0193 \\
\hline
\end{tabular}

Table 7 Dynamic changes in the suitable habitat area for $P$. villosa under different climate scenarios

\begin{tabular}{lllll}
\hline Climate scenario & Area $\left(\times 10^{4} \mathrm{~km}^{2}\right)$ & Area $\left(\times 10^{4} \mathrm{~km}^{2}\right)$ & Area $\left(\times 10^{4} \mathrm{~km}^{2}\right)$ & Are \\
\hline & Loss & Gain & Stable & Tota \\
Last Inter Glacial (LIG) & 1.2193 & 270.3439 & 66.2606 & 269.2 \\
Last Glacial Maximum (LGM) & 0.0449 & 52.2913 & 67.6280 & 52.2 \\
Representative concentration pathway (RCP) 2.6-2050 & 0.0905 & 17.9933 & 67.5910 & 17.9 \\
Representative concentration pathway (RCP) 2.6-2070 & 0.0261 & 22.0181 & 67.6961 & 21.9 \\
Representative concentration pathway (RCP) 8.5-2050 & 0.0905 & 17.9933 & 67.5910 & 17.9 \\
Representative concentration pathway (RCP) 8.5-2070 & 0.2209 & 65.9030 & 67.5632 & 65.6 \\
\hline
\end{tabular}

Table S1 Localities and genetic diversity indices for samples of P.villosa collected in the present study

\begin{tabular}{lllll}
\hline Population code & Location & Latitude $(\mathrm{N})$ & Longitude (E) & Altitude $(\mathrm{m})$ \\
\hline Populations of Group1 & Populations of Group1 & Populations of Group1 & Populations of Group1 & Populations of \\
1 & Uxin Banner, NMG & $38^{\circ} 52^{\prime} 18.9^{\prime \prime}$ & $109^{\circ} 10^{\prime} 18.2^{\prime \prime}$ & 1301 \\
2 & Hanggin Banner, NMG & $39^{\circ} 20^{\prime} 37.8^{\prime \prime}$ & $109^{\circ} 00^{\prime} 5.9^{\prime \prime}$ & 1314 \\
3 & Hanggin Banner, NMG & $40^{\circ} 01^{\prime} 59.2^{\prime \prime}$ & $108^{\circ} 28^{\prime} 34.6^{\prime \prime}$ & 1236 \\
4 & Hanggin Banner, NMG & $40^{\circ} 12^{\prime} 19.5^{\prime \prime}$ & $108^{\circ} 29^{\prime} 11.4^{\prime \prime}$ & 1229 \\
5 & Hanggin Banner, NMG & $40^{\circ} 26^{\prime} 4.6^{\prime \prime}$ & $108^{\circ} 37^{\prime} 52.9^{\prime \prime}$ & 1114 \\
6 & Dalad Banner, NMG & $40^{\circ} 20^{\prime} 25.8^{\prime \prime}$ & $109^{\circ} 31^{\prime} 21.5^{\prime \prime}$ & 1057 \\
7 & Dalad Banner, NMG & $40^{\circ} 15^{\prime} 39.1^{\prime \prime}$ & $110^{\circ} 00^{\prime} 43.1^{\prime \prime}$ & 1126 \\
8 & Dalad Banner, NMG & $40^{\circ} 11^{\prime} 57.4^{\prime \prime}$ & $111^{\circ} 07^{\prime} 21.4^{\prime \prime}$ & 1047 \\
9 & Sonid Left Banner, NMG & $43^{\circ} 40^{\prime} 36.5^{\prime \prime}$ & $113^{\circ} 26^{\prime} 57.9^{\prime \prime}$ & 1010 \\
10 & Sonid Left Banner, NMG & $43^{\circ} 26^{\prime} 4.1^{\prime \prime}$ & $114^{\circ} 18^{\prime} 57.8^{\prime \prime}$ & 1112 \\
11 & Sonid Left Banner, NMG & $43^{\circ} 16^{\prime} 49.7^{\prime \prime}$ & $114^{\circ} 26^{\prime} 13.1^{\prime \prime}$ & 1035 \\
Average & Zhengxiangbai Banner, NMG & $42^{\circ} 33^{\prime} 20.9^{\prime \prime}$ & $114^{\circ} 49^{\prime} 0.7^{\prime \prime}$ & 1211 \\
Populations of Group2 & & & \\
13 & Populations of Group2 & Populations of Group2 $^{\prime}$ & $\mathrm{Populations} \mathrm{of} \mathrm{Group2}^{\text {Populations of }}$ \\
14 & Zhenglan Banner, NMG & $42^{\circ} 41^{\prime} 0.0^{\prime \prime}$ & $115^{\circ} 59^{\prime} 0.0^{\prime \prime}$ & 1321 \\
\hline
\end{tabular}

Table S1 (Continued)

\begin{tabular}{|c|c|c|c|c|c|c|c|c|c|c|}
\hline 15 & Xilin Hot, NMG & $43^{\circ} 39^{\prime} 0.0^{\prime \prime}$ & $116^{\circ} 10^{\prime} 0.0^{\prime \prime}$ & 1111 & X. Su, 18, 031 & 5 & 25.70 & 0.6360 & 1.1604 & \\
\hline 16 & A & 20 & & 1056 & 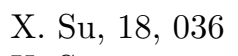 & 5 & 34.04 & 0.7757 & & \\
\hline 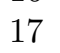 & & & & & & & & & & \\
\hline 8 & Son & & & & $\mathrm{X}$. & 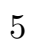 & & & & \\
\hline 9 & Zhe & & & 323 & & 5 & & & & \\
\hline 20 & Sor & & & 1111 & $\mathrm{X}$ & 3 & 9 & & & \\
\hline 1 & & & & 12 & & 2 & & & & \\
\hline 22 & Alxa Zuoqi, NMG & $40^{\circ} 37^{\prime} 0.0^{\prime \prime}$ & $104^{\circ} 35^{\prime} 0.0^{\prime \prime}$ & 1276 & X. Su, 18, 046 & 5 & 36.70 & 0.8144 & 1.2039 & \\
\hline
\end{tabular}




\begin{tabular}{|c|c|c|c|c|c|c|c|c|c|c|}
\hline 15 & Xilin Hot, NMG & $43^{\circ} 39^{\prime} 0.0^{\prime \prime}$ & $116^{\circ} 10^{\prime} 0.0^{\prime \prime}$ & 1111 & X. Su, 18, 031 & 5 & 25.70 & 0.6360 & 1.1604 & .1 \\
\hline 23 & A & & & & 12. & 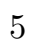 & & & & \\
\hline 24 & Alxa & & $103^{\circ} 58^{\prime} 20.7^{\prime \prime}$ & 30 & X. Su, 16, & 5 & .53 & 13 & 709 & \\
\hline 25 & Alxa & & & 03 & X. Su, 18, 008 & 5 & .00 & & 992 & \\
\hline 26 & Alxa & & & 457 & $\mathrm{X} . \mathrm{Su}$ & 5 & 53 & & 59 & \\
\hline 27 & Alxa & & & 70 & X. Su & 5 & .54 & & & \\
\hline 28 & Alxa & & & 60 & $\mathrm{X} . \mathrm{Sr}$ & 5 & 30.29 & & 28 & 1 \\
\hline 29 & Liang & & & 8 & X. S & 5 & 83 & & 44 & .1 \\
\hline 30 & trict, GS & & & 9 & $\mathrm{X} . \mathrm{Su}$ & 5 & 38.63 & 0.8 & 1.2138 & .19 \\
\hline 31 & Minqin County, GS & & & 1311 & X. Su, 18, 006 & 5 & 33.62 & & 1.1896 & .1 \\
\hline 32 & Alxa Zuoqi, NMG & & & 1241 & X. Su, 18, 013 & 5 & 32.47 & 0.7557 & 1.1890 & \\
\hline 33 & Alxa Zuoqi, NMG & $39^{\circ} 40^{\prime} 1.2^{\prime \prime}$ & $105^{\circ} 42^{\prime} 12.8^{\prime \prime}$ & 1025 & X. Su, 16, 051 & 5 & 19.23 & 0.5012 & 1.1359 & 0.1 \\
\hline
\end{tabular}

Table S1 (Continued)

\begin{tabular}{|c|c|c|c|c|c|c|c|c|c|c|}
\hline 34 & Alxa Zuoqi, NMG & $38^{\circ} 57^{\prime} 43.2^{\prime \prime}$ & $105^{\circ} 39^{\prime} 16.3^{\prime \prime}$ & 1458 & X. Su, 16, 052 & 5 & 25.45 & 0.6161 & 1.1523 & 0.133 \\
\hline 35 & Pingluo Xian, NX & $38^{\circ} 47^{\prime} 0.0^{\prime \prime}$ & $105^{\circ} 31^{\prime} 0.0^{\prime \prime}$ & 1179 & X. Su, 18, 015 & 5 & 34.40 & 0.7878 & 1.1977 & 0.177 \\
\hline 36 & Zhongwei City, NX & $37^{\circ} 25^{\prime} 29.1^{\prime \prime}$ & $104^{\circ} 40^{\prime} 5.0^{\prime \prime}$ & 1707 & X. Su, 16, 001 & 5 & 43.35 & 0.9256 & 1.2226 & 0.21 \\
\hline 37 & Lingwu County, NX & $38^{\circ} 07^{\prime} 9.8^{\prime \prime}$ & $106^{\circ} 30^{\prime} 57.8^{\prime \prime}$ & 1227 & X. Su, 16, 003 & 5 & 37.61 & 0.8150 & 1.2046 & 0.18 \\
\hline 38 & Ordos, NMG & $37^{\circ} 46^{\prime} 46.0^{\prime \prime}$ & $108^{\circ} 08^{\prime} 31.4^{\prime \prime}$ & 1344 & X. Su, 16, 005 & 5 & 38.15 & 0.8277 & 1.1990 & 0.18 \\
\hline 39 & Jingbian County, SX & $37^{\circ} 40^{\prime} 52.2^{\prime \prime}$ & $108^{\circ} 50^{\prime} 23.5^{\prime \prime}$ & 1328 & X. Su, 16, 007 & 5 & 35.49 & 0.7696 & 1.1984 & 0.17 \\
\hline 40 & Uxin Banner, NMG & $37^{\circ} 47^{\prime} 56.7^{\prime \prime}$ & $108^{\circ} 42^{\prime} 39.3^{\prime \prime}$ & 1254 & X. Su, 16, 008 & 5 & 26.78 & 0.6348 & 1.1438 & 0.13 \\
\hline 41 & Uxin Banner, NMG & $38^{\circ} 22^{\prime} 8.1^{\prime \prime}$ & $108^{\circ} 40^{\prime} 6.3^{\prime \prime}$ & 1286 & X. Su, 16, 010 & 5 & 26.00 & 0.6288 & 1.1436 & 0.13 \\
\hline 42 & Otog Banner, NMG & $38^{\circ} 53^{\prime} 0.0^{\prime \prime}$ & $108^{\circ} 18^{\prime} 0.0^{\prime \prime}$ & 1371 & X. Su, 18, 019 & 5 & 32.95 & 0.7545 & 1.1877 & 0.16 \\
\hline 43 & Otog Banner, NMG & $39^{\circ} 01^{\prime} 0.0^{\prime \prime}$ & $108^{\circ} 00^{\prime} 0.0^{\prime \prime}$ & 1358 & X. Su, 18, 017 & 5 & 54.29 & 1.1155 & 1.2908 & 0.27 \\
\hline Average & & & & & & & 32.02 & 0.7322 & 1.1817 & 0.1640 \\
\hline
\end{tabular}

$N$, number of individuals; polymorphic loci, the percentage of loci that are polymorphic out of total 1654 loci; $N$ a, observed number of alleles; $N$ e, effective number of alleles; $I$, Shannon's information index; $H$ e, expected heterozygosity.

NX, Ningxia; NMG, Neimenggu; SX, Shaanxi. GS, Gansu.

Table S2 Localities of 155 records used for niche modeling

\begin{tabular}{llllllll}
\hline Population code & Latitude $(\mathrm{N})$ & Longitude $(\mathrm{E})$ & Population code & Latitude $(\mathrm{N})$ & Longitude $(\mathrm{E})$ & Population code & La \\
\hline P1 & 49.2126 & 119.7292 & P23 & 43.3833 & 115.0000 & P45 & 42 \\
P2 & 45.5126 & 116.9779 & P24 & 43.3500 & 114.8500 & P46 & 42 \\
P3 & 44.0894 & 113.9219 & P25 & 43.3000 & 114.7667 & P47 & 42 \\
P4 & 43.9390 & 116.0704 & P26 & 43.2973 & 113.0510 & P48 & 42 \\
P5 & 43.8576 & 113.6554 & P27 & 43.2909 & 116.6604 & P49 & 42 \\
P6 & 43.7481 & 113.7815 & P28 & 43.2805 & 114.4370 & P50 & 42 \\
P7 & 43.7000 & 117.0000 & P29 & 43.2500 & 113.0000 & P51 & 42 \\
P8 & 43.6833 & 116.3167 & P30 & 43.2122 & 112.9788 & P52 & 42 \\
P9 & 43.6768 & 113.4494 & P31 & 43.1523 & 114.4681 & P53 & 40 \\
P10 & 43.6749 & 113.9785 & P32 & 43.1199 & 112.9065 & P54 & 40 \\
P11 & 43.6667 & 113.4500 & P33 & 43.0613 & 114.5072 & P55 & 42 \\
P12 & 43.6500 & 116.1667 & P34 & 43.0119 & 115.7574 & P56 & 42 \\
P13 & 43.6460 & 111.9699 & P35 & 42.9256 & 114.5646 & P57 & 42
\end{tabular}




\begin{tabular}{llllllll}
\hline Population code & Latitude (N) & Longitude (E) & Population code & Latitude (N) & Longitude (E) & Population code & La \\
\hline P14 & 43.6333 & 116.6500 & P36 & 42.8632 & 89.1928 & P58 & 41 \\
P15 & 43.6281 & 113.3760 & P37 & 42.8345 & 114.5676 & P59 & 41 \\
P16 & 43.6167 & 115.3333 & P38 & 42.7698 & 114.6434 & P60 & 41 \\
P17 & 43.6000 & 115.6500 & P39 & 42.7329 & 112.6404 & P61 & 41 \\
\hline
\end{tabular}

Table S2 (Continued)

\begin{tabular}{lllllllll}
\hline P18 & 43.5833 & 115.7500 & P40 & 42.7293 & 112.6501 & P62 & 40.8836 & 107.1434 \\
\hline P19 & 43.5491 & 113.2569 & P41 & 42.7167 & 116.0833 & P63 & 40.7791 & 107.4050 \\
P20 & 43.5154 & 114.1718 & P42 & 42.7028 & 114.7319 & P64 & 40.7619 & 107.4222 \\
P21 & 43.4667 & 115.0833 & P43 & 42.7000 & 108.9333 & P65 & 40.7458 & 104.5031 \\
P22 & 43.4345 & 114.3161 & P44 & 42.6833 & 115.9833 & P66 & 40.7418 & 107.3821 \\
P67 & 40.3882 & 110.0001 & P92 & 39.8000 & 108.7000 & P117 & 38.8535 & 105.7036 \\
P68 & 40.3833 & 104.7167 & P93 & 39.6670 & 105.7036 & P118 & 38.8380 & 105.6981 \\
P69 & 40.3817 & 109.3359 & P94 & 39.6630 & 108.7794 & P119 & 38.8367 & 99.6144 \\
P70 & 40.3405 & 109.5226 & P95 & 39.6281 & 103.0403 & P120 & 38.8330 & 105.6476 \\
P71 & 40.3366 & 106.9958 & P96 & 39.4333 & 102.7500 & P121 & 38.7833 & 105.5167 \\
P72 & 40.3256 & 107.0045 & P97 & 39.4073 & 102.3672 & P122 & 38.7566 & 110.1787 \\
P73 & 40.3252 & 107.0029 & P98 & 39.3771 & 99.8179 & P123 & 38.7392 & 109.1013 \\
P74 & 40.3108 & 105.8933 & P99 & 39.3616 & 110.1672 & P124 & 38.6650 & 105.8017 \\
P75 & 40.3055 & 109.9368 & P100 & 39.3476 & 102.0119 & P125 & 38.6500 & 108.9333 \\
P76 & 40.2884 & 109.9427 & P101 & 39.3438 & 109.0016 & P126 & 38.6410 & 108.9262 \\
P77 & 40.2609 & 110.0120 & P102 & 39.3333 & 104.9000 & P127 & 38.6269 & 106.5652 \\
P78 & 40.2431 & 109.9507 & P103 & 39.2667 & 104.9500 & P128 & 38.6106 & 108.8343 \\
P79 & 40.2379 & 105.9169 & P104 & 39.2167 & 103.7000 & P129 & 38.6000 & 108.7667 \\
\hline
\end{tabular}

Table S2 (Continued)

\begin{tabular}{lllllllll}
\hline P80 & 40.2054 & 108.4865 & P105 & 39.2078 & 101.6601 & P130 & 38.5304 & 105.6553 \\
\hline P81 & 40.1975 & 110.7404 & P106 & 39.1333 & 103.6667 & P131 & 38.3667 & 103.2833 \\
P82 & 40.1333 & 110.5000 & P107 & 39.1129 & 109.0366 & P132 & 38.3282 & 109.7580 \\
P83 & 40.1167 & 104.0500 & P108 & 39.0962 & 108.0956 & P133 & 38.3000 & 109.7000 \\
P84 & 40.0943 & 109.0196 & P109 & 39.0167 & 108.0000 & P134 & 38.2167 & 103.3000 \\
P85 & 40.0833 & 103.9500 & P110 & 38.9620 & 105.6545 & P135 & 38.1799 & 109.0588 \\
P86 & 40.0634 & 103.9141 & P111 & 38.9463 & 107.8719 & P136 & 38.1194 & 106.5161 \\
P87 & 40.0331 & 108.4763 & P112 & 38.9333 & 108.1333 & P137 & 38.1167 & 103.1667 \\
P88 & 40.0167 & 103.8833 & P113 & 38.9167 & 105.5167 & P138 & 38.1000 & 102.9833 \\
P89 & 39.9833 & 104.2000 & P114 & 38.8833 & 108.3000 & P139 & 38.0333 & 102.8667 \\
P90 & 39.8203 & 109.9558 & P115 & 38.8719 & 109.1717 & P140 & 38.0306 & 104.8136 \\
P91 & 39.8141 & 109.9729 & P116 & 38.8642 & 105.7319 & P141 & 37.9761 & 106.3286 \\
P142 & 37.9567 & 108.7709 & P147 & 37.6812 & 108.8399 & P152 & 37.4248 & 104.6681 \\
P143 & 37.9318 & 102.6068 & P148 & 37.6789 & 108.3090 & P153 & 37.3636 & 102.8363 \\
P144 & 37.9212 & 107.9943 & P149 & 37.5000 & 102.9000 & P154 & 36.3000 & 98.1000 \\
P145 & 37.7991 & 108.7109 & P150 & 37.4445 & 104.9394 & P155 & 35.9944 & 97.8869 \\
P146 & 37.7769 & 107.3913 & P151 & 37.4426 & 104.9383 & & & \\
\hline
\end{tabular}


Table S3 $F$ CT values for different numbers of population groups $(K)$ inferred by SAMOVA algorithm based on the AFLP dataset

\begin{tabular}{ll}
\hline $\mathrm{K}$ & Population grouping \\
\hline$K=2$ & $(1,2,3,4,5,6,7,8,9,10,11,12)(13,14,15,16,17,18,19,20,21,22,23,24,25,26,27,28,29,3$ \\
$K=3$ & $(1,2,3,4,5,6)(7,8,9,10,11,12)(13,14,15,16,17,18,19,20,21,22,23,24,25,26,27,28,29$, \\
$K=4$ & $(1,2,3,4,5,6)(7,8)(9,10,11,12)(13,14,15,16,17,18,19,20,21,22,23,24,25,26,27,28,29$ \\
$K=5$ & $(1,2,3,4,5,6)(7,8)(9,10,11,12)(13,14,16,17,18,19,20,21,22,23,24,25,26,27,28,29,30$ \\
$K=6$ & $(1,2,3,4,5,6)(7,8,9,10,11,12)(13)(14,15,16,17)(18,19,20,21,22,23,24,25,26,27,28$, \\
$K=7$ & $(1,2,3,4,5,6)(7,8,9,10,11,12)(13)(14,15,16,17)(18,20,21,22,24,25,26,27,28,29,30,3$ \\
$K=8$ & $(1,2,3,4,5,6)(7,8,9,10,11,12)(13)(14,15,16,17,18,19,22)(20,21,24,26,33,34)(23,32$, \\
$K=9$ & $(1,2,3,4,5,6)(7,8,9,10,11,12)(13)(14,15,16,17)(23,32,35)(18,20,21,22,24,25,26,27,2$ \\
$K=10$ & $(1,2,3,4,5,6)(7,8,9,10,11,12)(13)(14,15,16,17)(18,20,21,24,26,33)(19,22)(23,32,35$
\end{tabular}

\section{Figure legends}

Figure 1 Correlation of Mantel test between geographic distance and $F$ sT. A, Mantel test from 43 populations of $P$. villosa ; B, Mantel test from populations of Group 1; C, Mantel test from populations of Group 2

Figure 2 Dendrogram of $P$. villosa generated by unweighted pair group method analysis (UPGMA) cluster analysis from the genetic similarity matrix obtained using amplified fragment length polymorphism genetic distance (see Figure S1 for population codes)

Figure 3 Neighbor-Net split network of $P$. villosa based on amplified fragment length polymorphism dataset using Jaccard's distances. Lines of red and yellow represent Group 1 and Group 2, respectively

Figure 4 A two-dimensional plot of the principal coordinate analysis (PCoA) based on variation of amplified fragment length polymorphism markers for $P$. villosa (see Figure S1 for population codes)

Figure 5 Results of the Bayesian clustering analysis in STRUCTURE of 210 individuals representing $P$. villosa. A, ${ }^{K}$ valuesfromthemeanlog likelihoodprobabilitiesthroughSTRUCTU RErunswhereinferredcluster $(K)$ rangedfromonetoten; $\mathbf{B}$, Estimatedgeneticclus 2 , whereuniquecolorscorrespondtoassignmentatdif ferentclusters; $\mathbf{C}$, Geographicorigin from 43 populationsof $P$. villosaand codedgroupingaccordingtothestructureanalysis forthemodelwith $K=2$

Figure 6 Potentially suitable climatic distribution of $P$. villosa under different climate change scenarios in China

Figure 7 Present suitable climatic distribution of $P$. villosa in China

Figure 8 Spatial shifts for $P$. villosa under climate change scenarios

Figure 9 Results of the niche-identity test. A,Schoener's $D ; \mathbf{B}$, Warren's $I$. The arrow in each panel represents the observed niche similarity between occurrence points for the corresponding pair of clusters. The histograms represent the distribution of niche similarities obtained from pairs of pseudo niches constructed by random resampling of occurrence points of the two clusters

Figure S1 Localities of Group 1 (red), Group 2 (yellow) sampled of P. villosa in the present study

Figure S2 Fluorescently-labeled AFLPs generated using different primer combinations. A, $E-\mathrm{AAC} / M$ CAA; B, $E$-AAG/ $M$-CAC; C, $E$-ACA $/ M$-CAG; D, $E$-ACT/ $M$-CAT; E, $E$-ACC/ $M$-CTA; F, $E-\mathrm{ACG} / M$ -CTC; G, $E-\mathrm{AGC} / M-\mathrm{CTG} ; \mathbf{H}, E-\mathrm{AGG} / M-\mathrm{CTT}$

Figure S3 The mean AUC of the test samples of P. villosa based on the MaxEnt model 

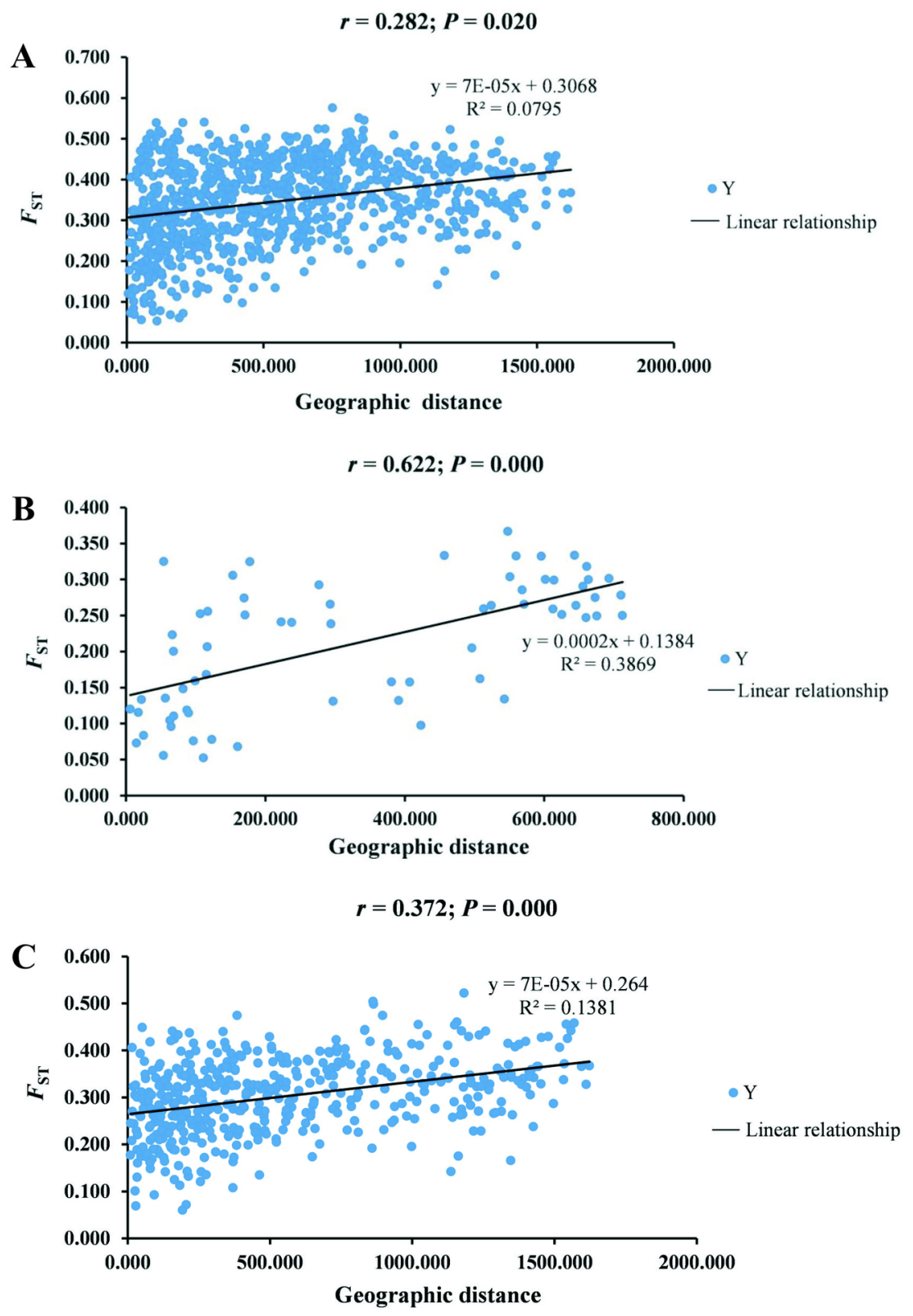

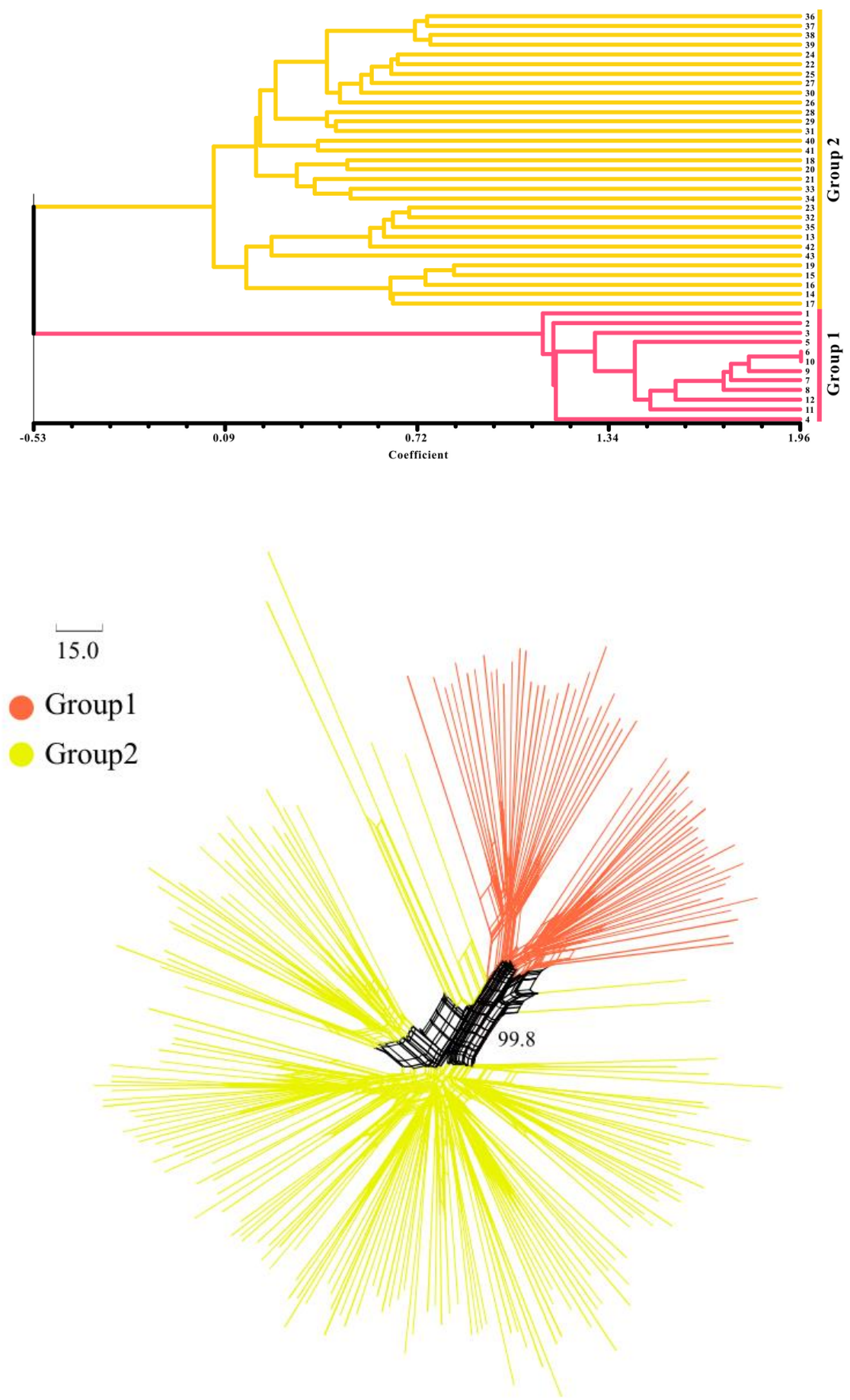


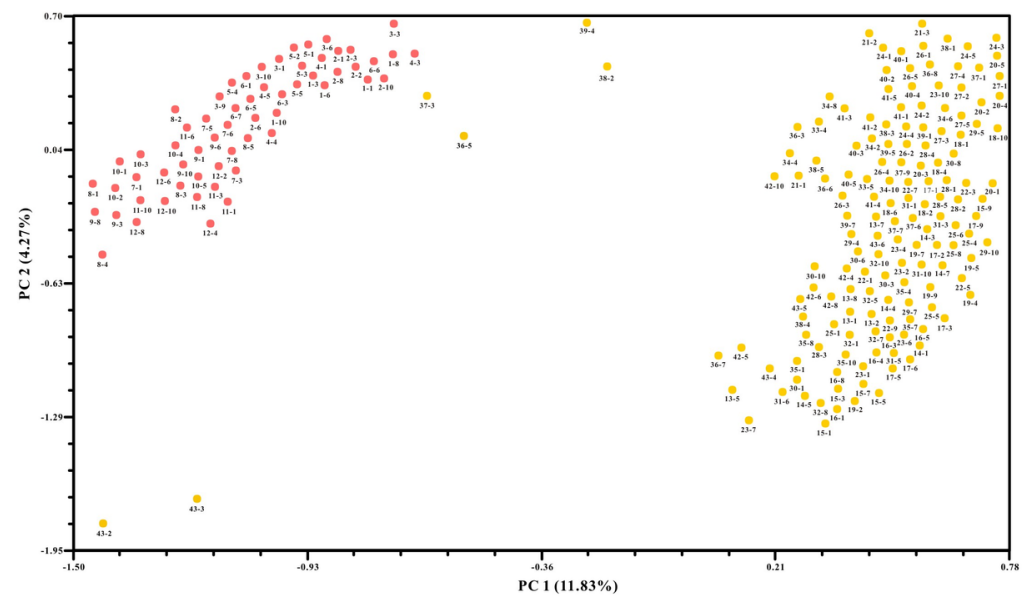



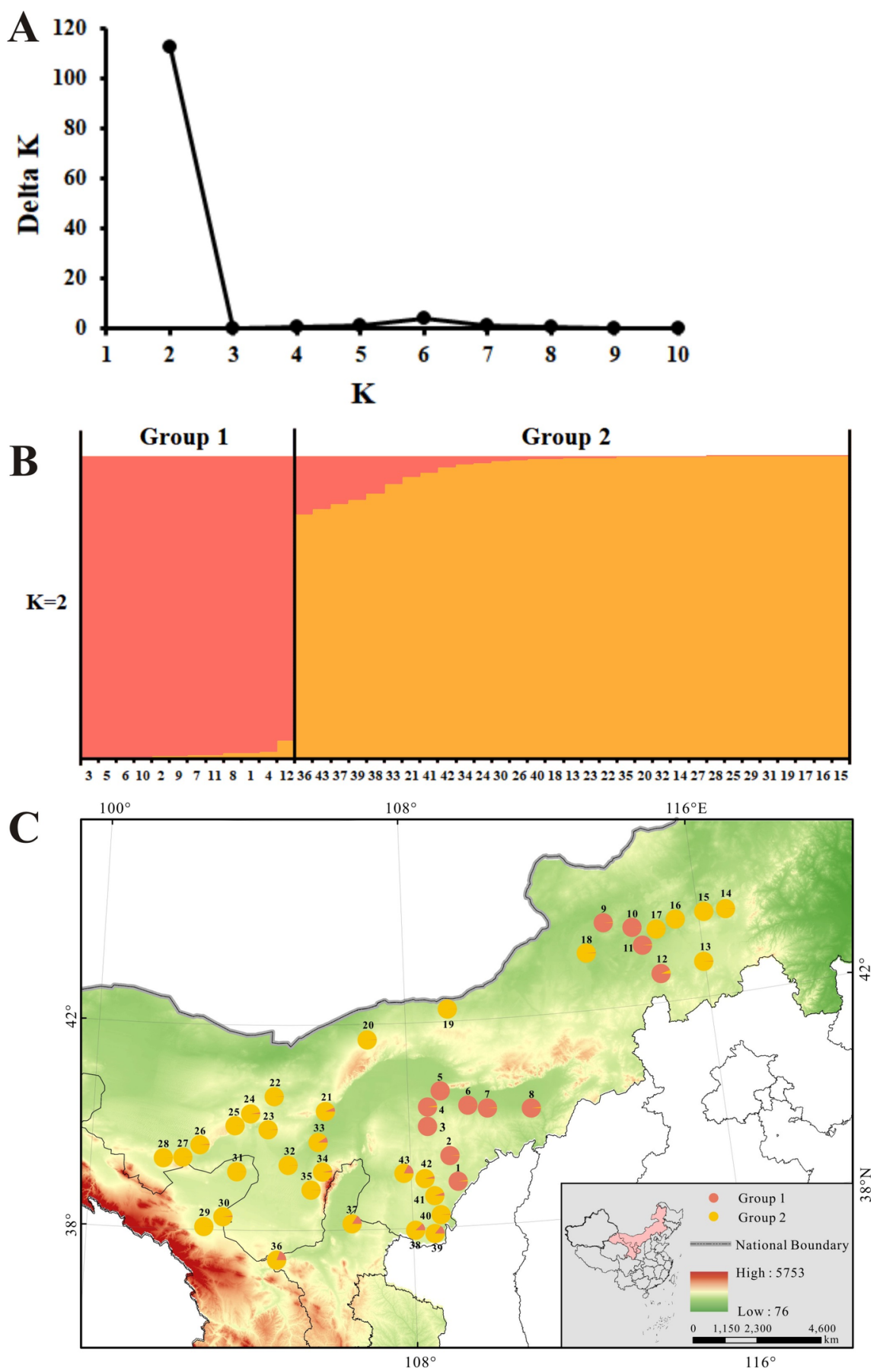
LIG

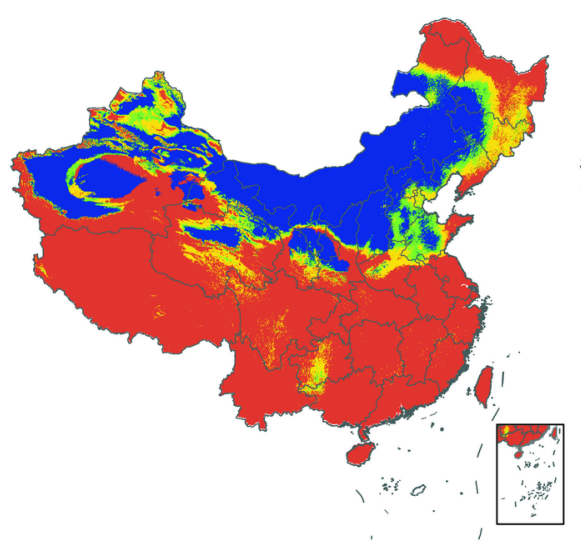

2050s, RCP2.6

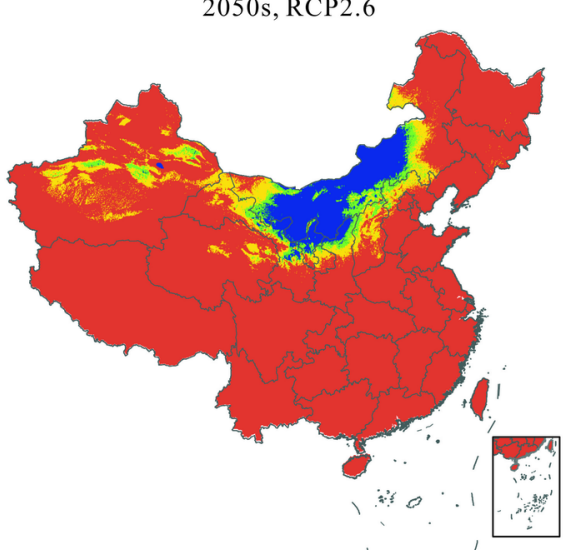

2050s, RCP8.5

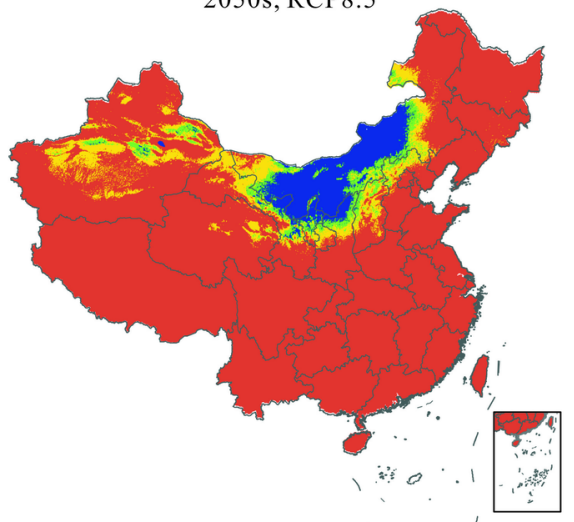

Suitable index
Unsuitable habitat

Moderately suitable habitat
LGM

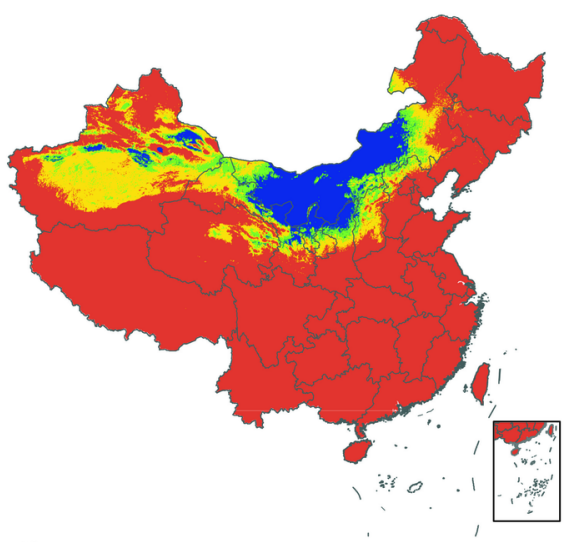

2070s, RCP2.6

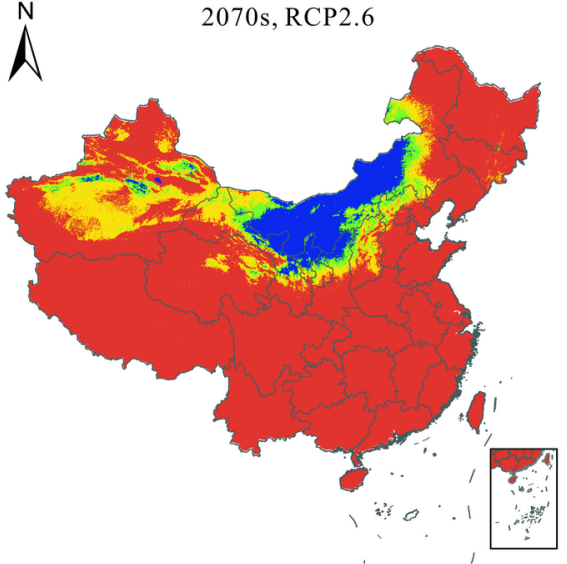

2070 s, RCP 8.5

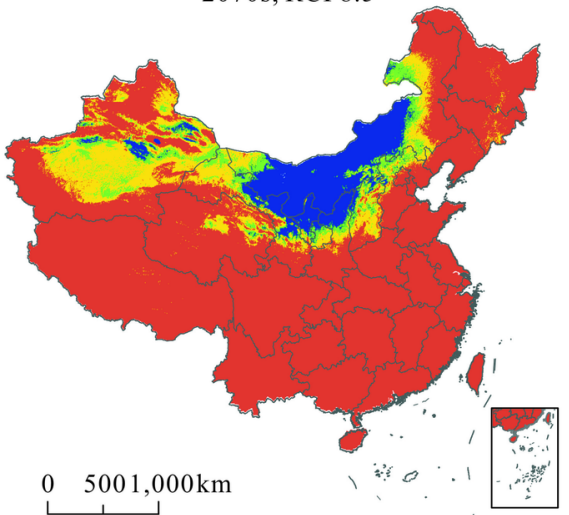

Poorly suitable habitat

Highly suitable habitat 


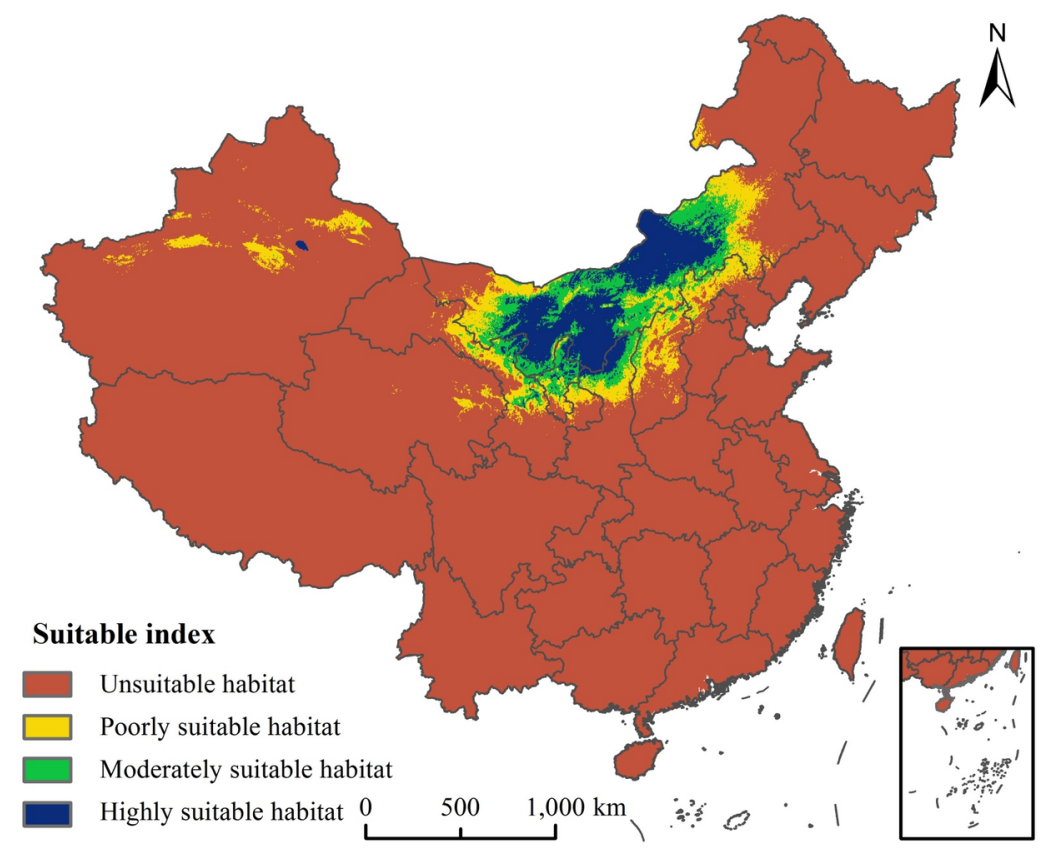


LIG

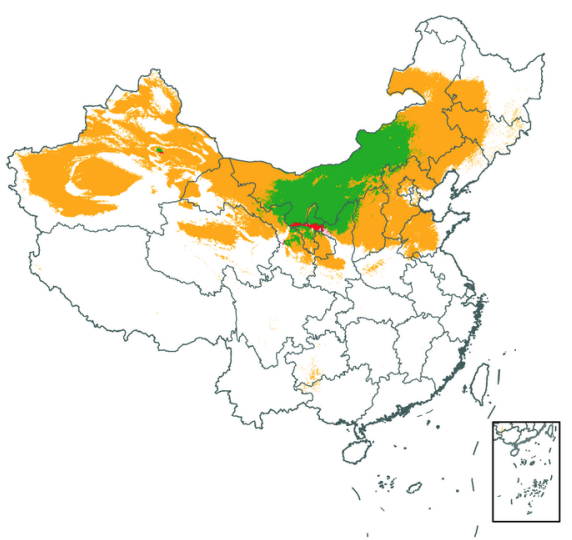

2050s, RCP2.6
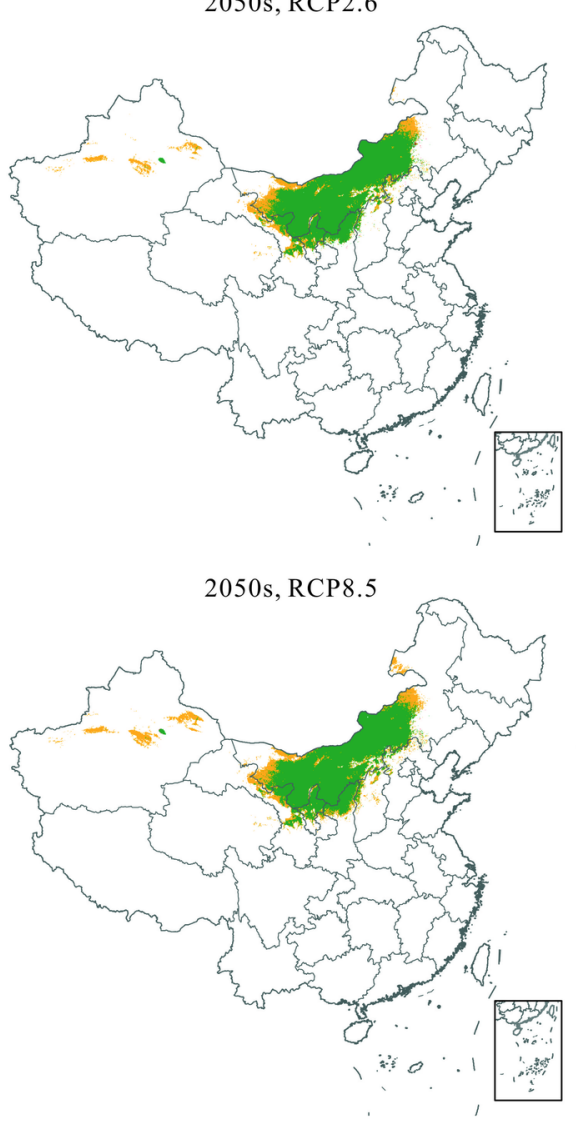

Legend

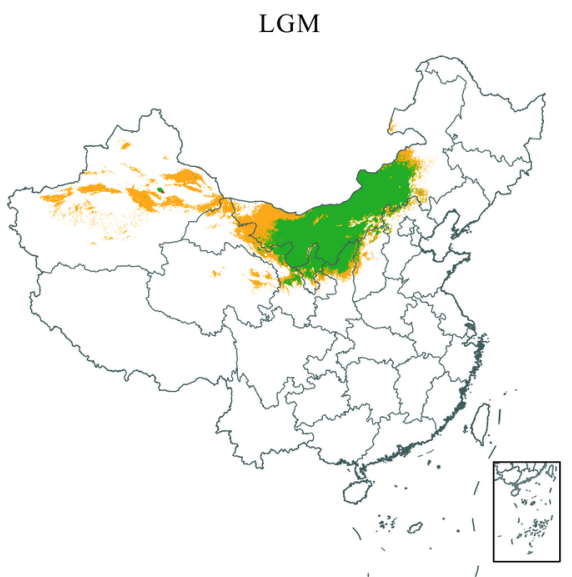

2070s, RCP2.6

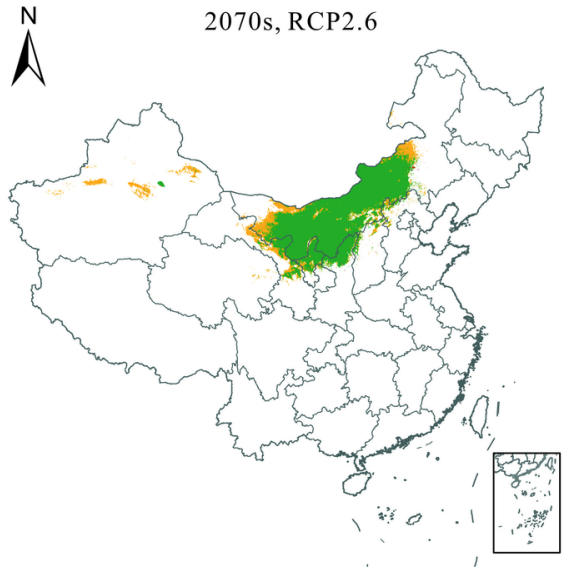

2070s, RCP8.5

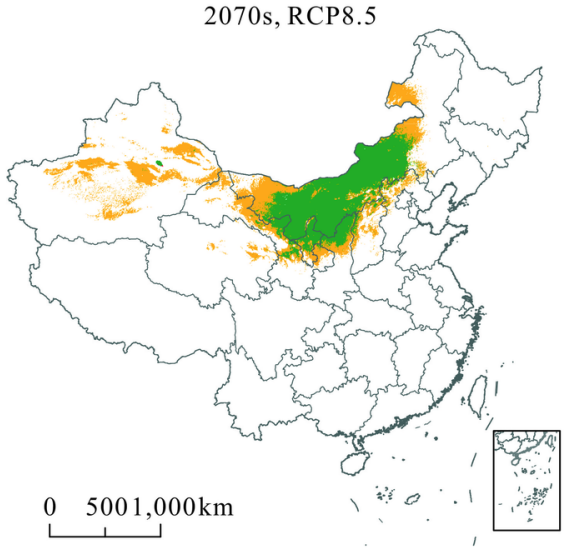

Stable 


\section{Cluster 1 vs. Cluster 2}
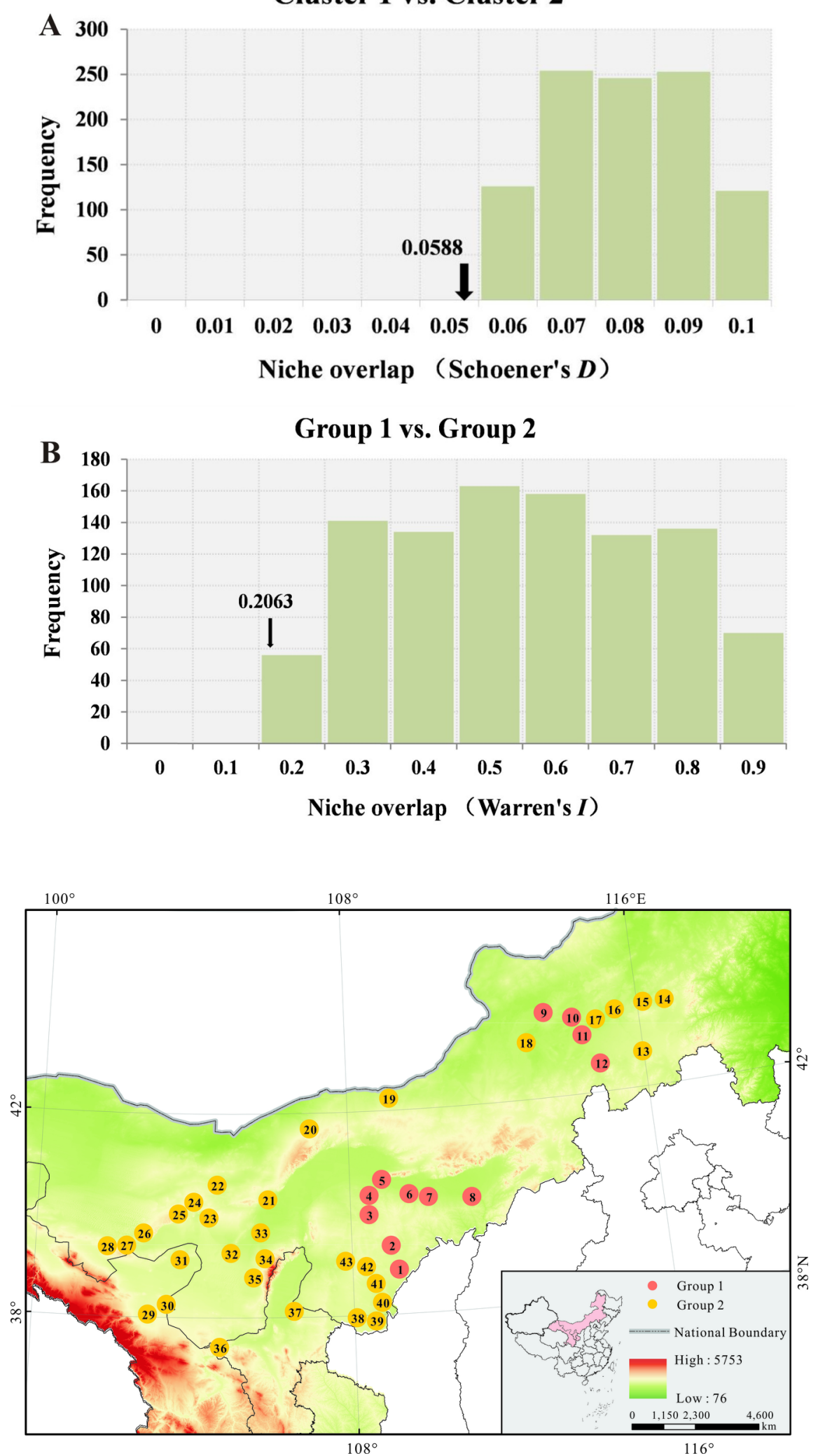

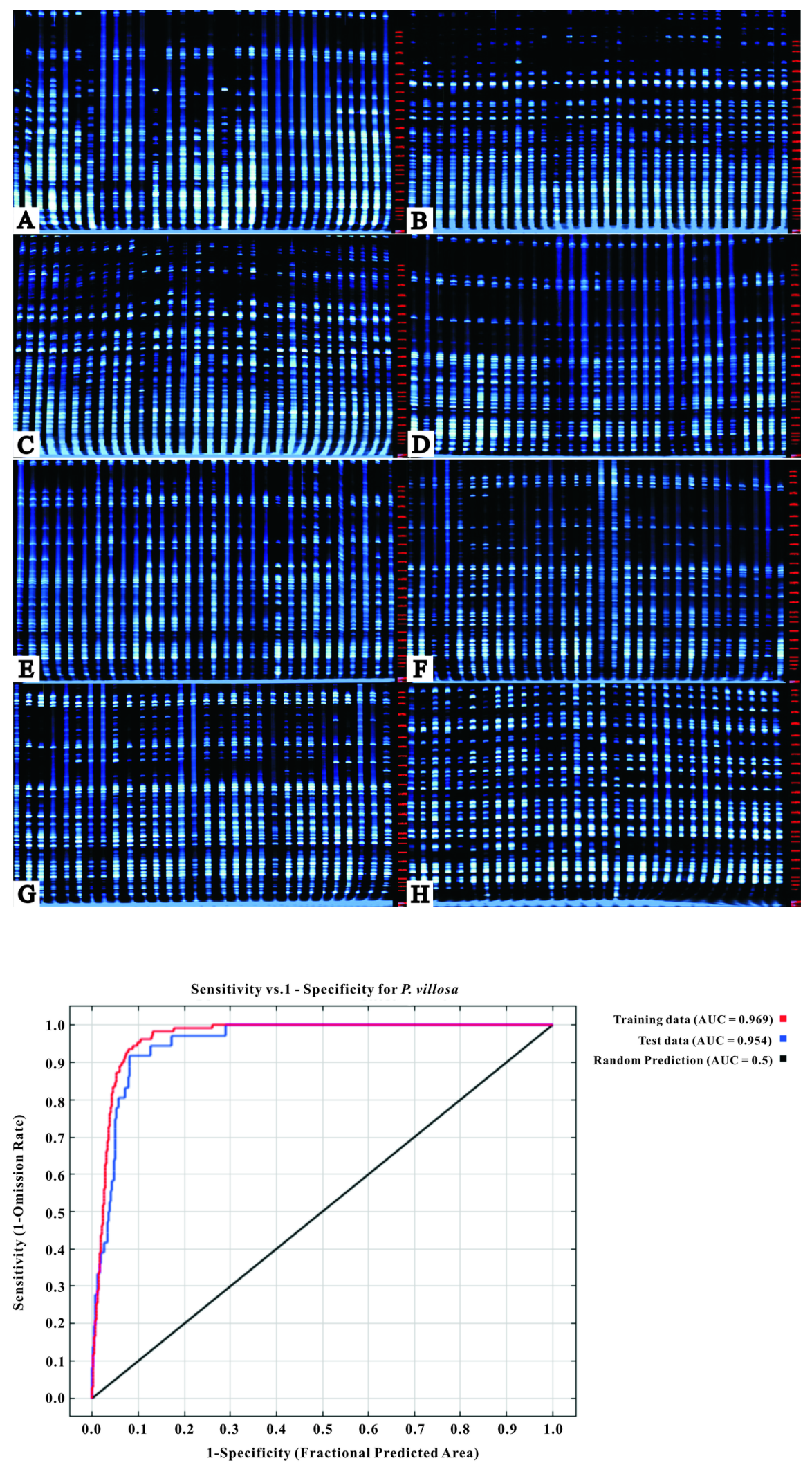